\title{
A critical analysis of extraction techniques used for botanicals: Trends, priorities, industrial uses and optimization strategies
}

\author{
Tarun Belwal ${ }^{\mathrm{a}}$, Shahira M. Ezzat ${ }^{\mathrm{b}, \mathrm{c}}$, Luca Rastrelli ${ }^{\mathrm{d}}$, Indra D. Bhatt ${ }^{\mathrm{a}}$, Maria Daglia ${ }^{\mathrm{e}}$, Alessandra Baldi ${ }^{\mathrm{e}}$, \\ Hari Prasad Devkota ${ }^{\text {f, g }}$, Ilkay Erdogan Orhan ${ }^{\text {h }}$, Jayanta Kumar Patra ${ }^{i}$, Gitishree Das ${ }^{i}$ C. Anandharamakrishnan ${ }^{j}$, \\ Lourdes Gomez-Gomez ${ }^{\mathrm{k}}$, Seyed Fazel Nabavi ${ }^{1}$, Seyed Mohammad Nabavil, *, Atanas G. Atanasov ${ }^{\mathrm{m}, \mathrm{n}, \text { ** }}$ \\ ${ }^{a}$ G. B. Pant National Institute of Himalayan Environment and Sustainable Development, Kosi-Katarmal, 263643, Almora, Uttarakhand, India \\ ${ }^{\mathrm{b}}$ Department of Pharmacognosy, Faculty of Pharmacy, Cairo University, Giza, Egypt \\ ${ }^{c}$ Department of Pharmacognosy, Faculty of Pharmacy, October University for Modern Science and Arts (MSA), 6th October, 12566, Egypt \\ d Dipartimento diFarmacia, University of Salerno, via Giovanni Paolo II, 84084, Fisciano, Italy \\ e Department of Drug Sciences, Medicinal Chemistry and Pharmaceutical Technology Section, Pavia University, VialeTaramelli 12, 27100 Pavia, Italy \\ ${ }^{\mathrm{f}}$ School of Pharmacy, Kumamoto University, 5-1 Oe-honmachi, Chuo ku, Kumamoto 862-0973, Japan \\ g Program for Leading Graduate Schools, Health life Science: Interdisciplinary and Glocal Oriented (HIGO) Program, Kumamoto University, Kumamoto, Japan \\ h Department of Pharmacognosy, Faculty of Pharmacy, Gazi University, 06330, Ankara, Turkey \\ ${ }^{\mathrm{i}}$ Research Institute of Biotechnology \& Medical Converged Science, Dongguk University-Seoul, Goyang-si 10326, Republic of Korea \\ ${ }^{\mathrm{j}}$ Computational Modelling and Nanoscale Processing Unit, Indian Institute of Food Processing Technology, Thanjavur, 613005, Tamil Nadu, India \\ ${ }^{k}$ Facultad de Farmacia, Universidad de Dastilla-La Mancha, Campus Universitario S/n, 02071 Albacete, Spain \\ ${ }^{1}$ Applied Biotechnology Research Center, Baqiyatallah University of Medical Sciences, Tehran, Iran \\ ${ }^{\mathrm{m}}$ Department of Pharmacognosy, University of Vienna, Althanstrasse14, 1090 Vienna, Austria \\ ${ }^{\mathrm{n}}$ Molecular Biology Department, Institute of Genetics and Animal Breeding of the Polish Academy of Sciences, Jastrzebiec, Poland
}

\section{A R T I C L E INFO}

Article history:

Available online $\mathrm{xxx}$

Keywords:

Bioactive compounds

Advanced extraction techniques

Green extraction

Plant matrices

Ultrasonic assisted extraction (UAE)

Supercritical fluid extraction (SFE)

Microwave assisted extraction (MAE)

Pressurized liquid extraction (PLE)
A B S T R A C T

Plant extracts have been long used by the traditional healers for providing health benefits and are nowadays suitable ingredient for the production of formulated health products and nutraceuticals. Traditional methods of extraction such as maceration, percolation, digestion, and preparation of decoctions and infusions are now been replaced by advanced extraction methods for increased extraction efficiency and selectivity of bioactive compounds to meet up the increasing market demand. Advanced techniques use different ways for extraction such as microwaves, ultrasound waves, supercritical fluids, enzymes, pressurized liquids, electric field, etc. These innovative extraction techniques, afford final extracts selectively rich in compounds of interest without formation of artifacts, and are often simple, fast, environmentally friendly and fully automated compared to existing extraction method. The present review is focused on the recent trends on the extraction of different bioactive chemical constituents depending on the nature of sample matrices and their chemical classes including anthocyanins, flavonoids, polyphenols, alkaloids, oils, etc. In addition, we review the strategies for designing extraction, selection of most suitable extraction methods, and trends of extraction methods for botanicals. Recent progress on the research based on these advanced methods of extractions and their industrial importance are also discussed in detail.

(C) 2017

\section{Introduction}

Extraction is a fundamental process for separation and recovery of bioactive compounds from plants. It converts real matrix into a sample suitable for subsequent analytical procedure. From ancient times, sample preparations have been conducted by various ethnic groups worldwide, using decoction, maceration, infusion, digestion and percolation methods for making extract and thus utilize plants for their therapeutic effect (Fig. 1a). These extraction techniques have come into light during the $11^{\text {th }}$ century and have been reported to be the old-

\footnotetext{
* Corresponding author.

** Corresponding author. Department of Pharmacognosy, University of Vienna, Althanstrasse 14, 1090 Vienna, Austria.

Email addresses: nabavi208@gmail.com (S.M. Nabavi); a.atanasov.mailbox@ gmail.com (A.G. Atanasov)
}

est techniques used so far which also form the basic principles of advanced extraction techniques. Continuing to the modernization and industrial growth era, during the 18th century an improved extraction technique "Soxhlet Extraction" was introduced, which is an advanced form of the digestion and decoction methods. However, these conventional extraction techniques including Soxhlet, have the disadvantages of using larger volume of solvent and also take longer time for extraction of compounds with lower yield. The exponentially increasing demand of herbal products and/or extracts for wider and safer applications, timely availability of high quality products with low cost of processing and higher yield are the needs of the growing herbal/ nutraceutical medicine based industries. To meet these challenges, there is an increased demand for alternative and non-conventional extraction techniques (Fig. 1b), which have been introduced in various time span. These include, microwave assisted extraction (MAE), su- 
(a)

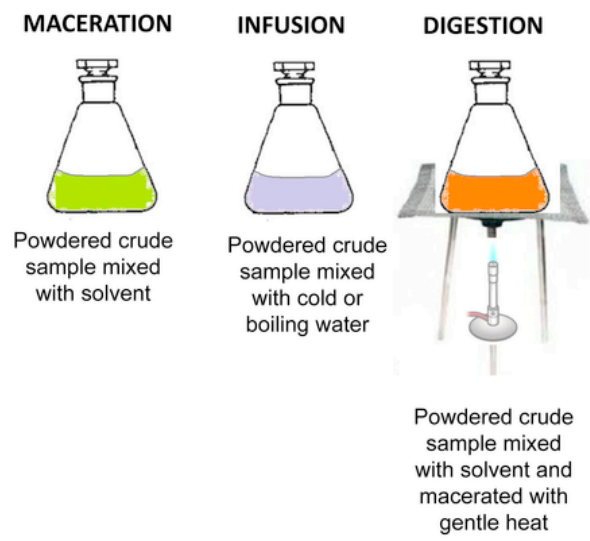

Conventional Extraction Methods

DECOCTION

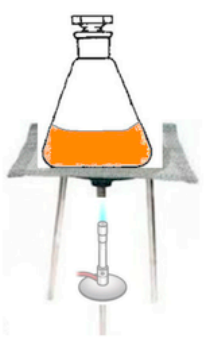

Powdered crude sample mixed with water and boiled
PERCOLATION

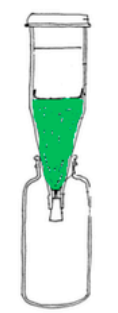

Powdered crude sample mixed with solvent is extracted in a percolator

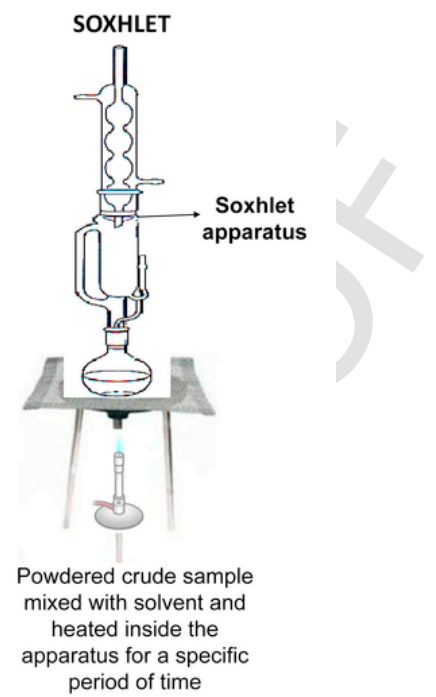

(b) Advanced Extraction Methods

MAE

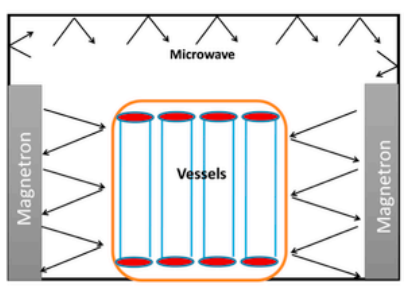

Sample mixed with organic

solvent and heated by

microwaves through ionic

conductance and dipole rotation
SFE

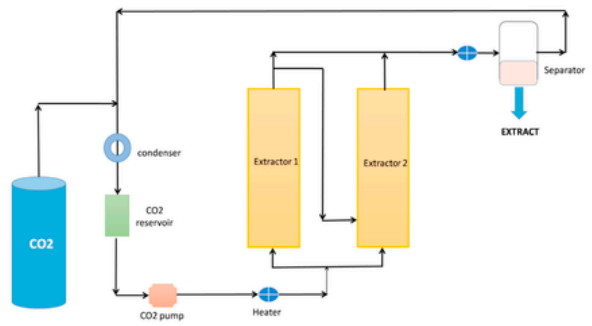

Sample extracted by using $\mathrm{CO}_{2}$ as a solvent which depend on the critical point
UAE

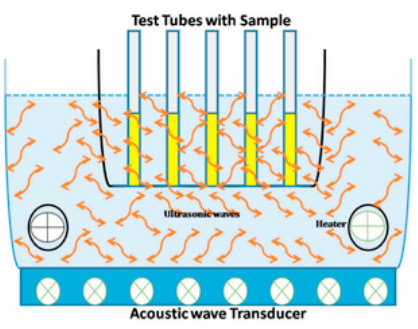

Sample extracted by using organic solvent which under ultrasonic wave form cavitation bubbles

Fig. 1. Some of the (a) conventional and (b) advanced extraction techniques with their mechanism of extraction.

percritical fluid extraction (SFE), pressurized liquid extraction (PLE), ultrasound assisted extraction (UAE), pulsed electric field assisted extraction (PEF) and enzyme assisted extraction (EAE). These techniques are known for their short extraction time, reduced volume of organic and hazardous solvents, and are very simple to perform, achieving a higher extraction yield with lower energy consumption, thus categorized under 'Green Extraction' techniques [1]. As such, extraction techniques are defined as green extraction, if they use alternative solvents, reduce energy consumption and ensure safety and high quality of the extract [2].

The use of microwave energy for extraction from biological matrices was first described in 1986 by Ganzler [3]. Two types of instruments are available for MAE, the most commonly used is the extraction in a closed vessel under controlled pressure and temperature, while the second consists of an open extraction vessel under atmospheric pressure conditions and the maximum temperature that can be reached based on the solvent boiling point. MAE uses electromagnetic radiation $(300 \mathrm{MHz}-300 \mathrm{GHz})$, which is used to heat the sample by continuous dipole rotation (dielectric heating) and by the frictional resistance to the ion flow, both of which induce an increase in thermal energy, thus increasing the extraction efficiency [4]. The extraction efficiency under microwave depends on the nature of both solvent and sample. The solubility of the different compounds to be extracted can be maximized by fixing the solvents mixture ratio and controlling the temperature. MAE has a number of advantages, including the extraction of both volatile (solvent extraction) and non-volatile (dry extraction) compounds. Nevertheless, many laboratories have used the microwave energy for synthetic, analytical and processing applications.

UAE was introduced in around 1950 for making beer from hops $[5,6]$. Since then, using this technique, different types of secondary metabolites from a variety of plant matrices have been efficiently extracted and analyzed. UAE uses ultrasonic energy $(>20 \mathrm{kHz})$ for extraction using either ultrasonic bath and/or ultrasonic probe. It works on the principle of making cavitation bubbles which collapse and produce higher shear, which results in complete extraction. More specifically, during UAE of plant material, the suspended powdered sample induces asymmetric bubble collapse, thus results in more efficient extraction [7]. UAE also generates reactive oxygen species (ROS) during sonolysis [8], which results in lower concentration and degradation of some of the compounds $[9,10]$. Additionally, the kind of pretreatment applied on the plant material to be treated will also contribute to extraction performances. UAE has been widely investigated for its application on natural products [11] allowing the extraction at 
lower temperatures than normally used, reduction of solvent volumes and enhancing extraction and purity.

In 1940s, the first application of electric fields on food was introduced as a method of increasing the extraction of juice from fruits, which today is one of the major fields of PEF application [12]. In the 1960s, Sale and Hamilton [13] studied the microbial inactivation effect exerted by PEF. After this interesting finding, in the 1980s, PEF applications were developed for the preservation of foods. In addition to its application in food preservation processes (due to enzymatic and microbial inactivation), PEF technology is currently being applied as a pre-treatment in the extraction processes of fruits and vegetables, as wine quality enhancer, in the recovery of valuable compounds, and in lipid extraction for bio-refinery [14]. It is a non-thermal technology based on the electroporation phenomenon on cell membranes, which occurs when a moderate or high electric field $(0.1-50 \mathrm{kV} / \mathrm{cm})$ is applied to living cells, with subsequent short duration pulses $(\mu \mathrm{s})$, leading to a loss of influx and efflux transport selectivity, increasing permeability and promoting mass transport $[14,15]$. The first patent on PEF extraction from plant materials was registered in 2009, based on observed positive effects of electroporation on the permeability of plant tissues. Facilitating the efflux of water and solutes from intracellular to extracellular spaces enhances the extraction of phytochemicals, with the patent specifically focusing on carotenoids. A maximum extraction yield percentage of $68.8 \%$ lycopene from tomatoes was obtained in comparison with untreated samples $[16,17]$.

Enzyme-assisted extraction (EAE) is another advanced extraction technique which has been developed to reduce the use of solvents, as employed in traditional extraction procedures, reducing environmental impact and energy process inputs [18]. This innovative extraction method is based on increasing the permeability of cell plasmatic membrane or cell wall through the hydrolytic action of enzymes ( $\alpha$-amylase, cellulase, pectinase and protease), which aids the extraction of the compounds of interest, such as natural pigments, polysaccharides, flavors and bioactive compounds. EAE allow the use of an aqueous solution and mild processing conditions to obtain an extract for various industrial applications. The enzymes used are mostly derived from microorganisms, but also could be obtained from plants and animals [19].

During recent time, greater emphasis has been given on green extraction of compounds. This can be achieved by the application of sub- and supercritical fluids $(\mathrm{ScF})$ in the extraction process [20]. $\mathrm{ScF}$ can be applied in many ways; as a reaction medium, as solvents for precipitation and micronization, as mobile phase for chromatography, and as solvent for extraction process [21]. Utilizing the ScF, it is equitable to adopt the supercritical fluid extraction (SFE) process at industrial scale for separation of components having high commercial value including nutraceutical, pharmaceutical and food additives with high feed to solvent ratio [20]. The SFE process is an alternative sample preparation method that reduces the use of organic solvents and increases the output. SFE involves use of gases, usually $\mathrm{CO}_{2}$ for the extraction process. The critical point that is the optimum temperature and pressure at which the substance can vaporize is very important in SFE, which is more profitable over the classical extraction methods considering the environment. It is the most technologically advanced extraction system [22] and finds widespread application in environmental, chemical, food, agriculture, pharmaceutical and nutraceutical industries $[21,23]$. In another $\mathrm{ScF}$ method, supercritical antisolvent fractionation (SAF) uses $\mathrm{CO}_{2}$ as antisolvent, because polar and high molecular weight compounds insoluble in $\mathrm{CO}_{2}$ can be recovered in separator chamber and separated from non-polar components of the matrix. SAF provides a continuous contact between $\mathrm{Sc}-\mathrm{CO}_{2}$ and polar liquid mixture under pressurized chamber. This will allow the precipitation of polar components from the liquid mixture insoluble in $\mathrm{Sc}-\mathrm{CO}_{2}$, while the other non-polar components dissolved in $\mathrm{Sc}-$ $\mathrm{CO}_{2}$ flow and are recovered by downstream pressure reduction system $[24,25]$. The main advantage of SAF is the lipophilic character of $\mathrm{CO}_{2}$ that allows separation and concentration of polar compounds from organic extracts. SAF permits to work at reduced temperatures, in absence of oxygen and light. Furthermore, $\mathrm{CO}_{2}$ is inexpensive, recyclable and non-toxic.

In the recent years, numerous applications of pressurized liquid extraction (PLE) have been developed concerning the extraction of bioactive compounds from plants [26,27] along with comparison of PLE extracts obtained according to pharmacopoeia monographs [28]. This method using water as a solvent is extremely suitable for recovery of bioactive compounds and seems to be milder compared to other techniques, avoiding the production of artifacts. This research approach responds to the need of our society that requires a reduction of wastes, as well as their valorisation, transforming waste into a resource. Recently, a new type of cavitation extraction method has been introduced in the year 2009, which generates cavitation by negative pressure and named as negative pressure cavitation extraction (NPCE). Among many advantages, such as lesser extraction time, green extraction, higher efficiency, etc., NPCE has been widely used in the extraction of thermolabile compounds. Its efficiency has not been found lower than that of ultrasonic cavitation, and a number of bioactive compounds have been extracted using NPCE [29-35].

All these extraction techniques have proven effective in extraction of various bioactive compounds from vegetal matrices and have followed basic principles of maximizing the yield of extraction; adapting demands of industry; clarifying impurities and toxic compounds; preventing deterioration and loss of functionality during extraction; thus ensuring food grade of final products [36]. Among all the aforementioned extraction techniques, it is crucial to pick the most appropriate extraction method. Therefore, one should pay a great attention to some critical points during extraction. For instance; factors, like use of the correctly identified plant material (hard/soft), appropriate collection time of the plant and its part, drying, grinding, and powdering method, particle size, solvent selection for targeted compounds, number of extraction cycles, temperature, extractor type and design, may influence the extraction yield and quality of the extract [37-39].

Various review have been published in this direction, mainly deals with either a single/few method of extraction [40-43], focused on a specific compound and its class $[44,45]$ or tissue/plant type $[44,46]$, deals with different extraction techniques for a specific compound class [45] or basic operating process or not recently reviewed $[47,48]$. However, some of the recently published reviews have limited scope of either dealing with compound classes [49] or extraction techniques [7,8,50-52]. Thus, our present review will not only provide recent advances in extraction but also have wider scope in understanding various extraction methods used over chemical compounds and its selection criteria over wider variables/factors. Also, the trends of extraction techniques, industrial relevance/importance and optimization design will help to understand and prioritize the wider possibilities for selection of suitable extraction methods (Fig. 2).

\section{Critical analysis of extraction methods}

\subsection{Compound classes and tissue matrix types}

Plants are being used for various purposes i.e. food, fuel, fodder, goods, etc. and also to extract bioactive compounds (i.e. polyphenols, alkaloids, anthocyanins, flavonoids, phenolic acids, carbohydrates, polysaccharides, essential oils, etc.) which are found effective against a vast number of health complications. The successful extraction of these compounds from different botanicals depends on their

physico- 


\section{$\begin{array}{lll}\text { Plant Part } & \text { Chemical class } \quad \text { Extraction Method }\end{array}$}

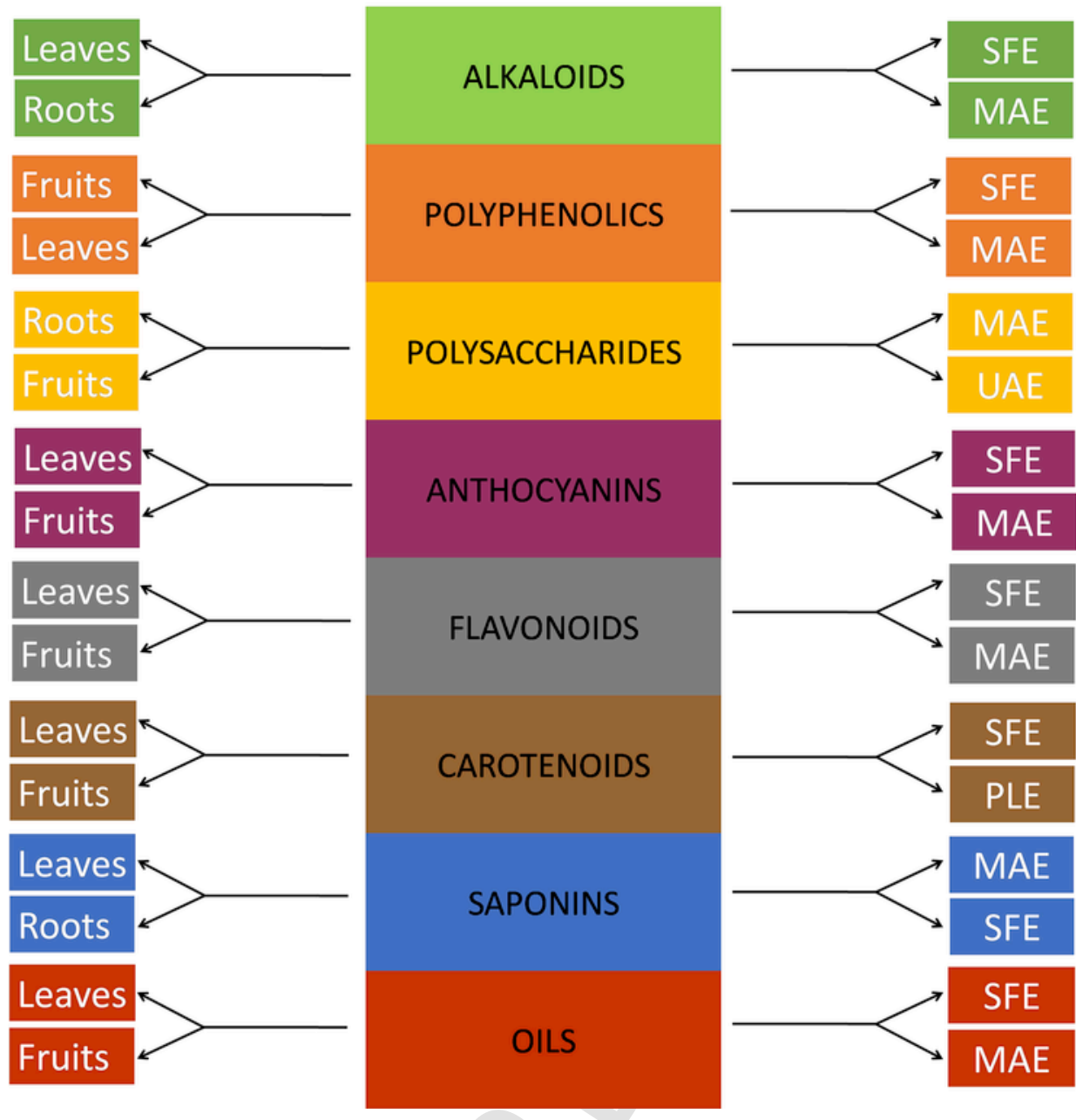

Fig. 2. Preferred advanced extraction techniques and plant parts used for extraction of different compounds.

chemical properties as well as plant parts and tissue matrices type. Cell structure, bound or free form of compounds, moisture content, and particle size are among the most important properties of a plant subjected to extraction as describe by Vinatoru et al. [7]. These properties must be considered in designing extraction methods. Moreover, extraction efficiency or condition may vary depending on the physiochemical properties of the compound of interest. As such, various extraction methods have been tested to extract compounds from different plant parts and some of them are discussed below.

\subsubsection{Extraction of polyphenols}

Bobinaitè et al. [53] studied the application of PEF as a pre-treatment in the juice extraction process starting from blueberry fruits and their by-products (press cake) to increase the polyphenol content [53]. The results showed that in mild PEF-treated samples, the level of total phenolic and anthocyanin content significantly increases compared to non-treated samples, for both juice and cake extracts [53]. Almost at the same time, Zderic [54] tried to develop new process to extract polyphenolics from tea leaves, as conventional tea processing methods (such as cutting, rolling, drying) and the high temperatures required to destroy remaining enzymes, lead to a loss of these bioactive molecules [54]. The authors found that under optimum PEF conditions $(1.1 \mathrm{kV} / \mathrm{cm}$ field intensity, and 50 pulses with a
$0.0001 \mathrm{~s}$ duration) the extraction yield was $32.5 \%$ [54]. Luengo et al. [55] executed a study on improving polyphenol extraction from orange peels. In PEF-pretreated samples, the total polyphenol extraction yield increased by $153 \%$ when a PEF of $5 \mathrm{kV} / \mathrm{cm}$ was applied, in comparison with non-pretreated samples [55]. Moreover, an increase in naringenin and hesperidin content was observed; the increase in naringenin levels ranges from 1.3 to $4.6 \mathrm{mg} / 100 \mathrm{~g}$ of fresh orange peels, while for hesperidin the increase ranges from 1 to $3.1 \mathrm{mg} / 100 \mathrm{~g}$ of fresh orange peels. Consistently, PEF require no use of organic solvents and thus have greater acceptability in formulating toxic free extract [55]. For the extraction of high polyphenol content juice from Amla (Phyllanthus emblica), an Indian fruit widely used for its health properties, Bansal et al. [56] used PEF technology, focusing their attention on quercetin and ellagic acid [56]. Amla juice produced using conventional techniques is characterized by low quality in terms of phenolic compounds and vitamins. The results of this study show that the application of electric field with strength of $22 \mathrm{kV} / \mathrm{cm}$, for $500 \mu$ s, increases quercetin and ellagic acid concentrations in amla juice, nine times and two times respectively, compared to samples processed under conventional extraction methods [56]. Further, PLE was also found suitable for polyphenolic extraction over UAE and conventional extraction methods [57]. 
Using separation and detection method, a rapid and sensitive PLE/ HPLC-ESI-MS/MS method was developed for quantification of bioactive components of Radix Astragali [58]. In addition, PLE/ GC-MS was used for the identification and quantification of ferulic acid, ligustilide and other phthalides in Angelica sinensis [59]. Other articles have shown quicker and high yield extraction of polyphenols via PLE with respect to conventional techniques [60-62].

Demanding of high-quality polyphenols increases because of their wider applications in nutraceuticals, pharmaceuticals, and cosmeceuticals industries. To meet up the increasing demand of polyphenolics, SFE was introduced. As such, Da Porto [63] used SFE for maximize extraction of polyphenolics from the seeds of Vitis vinifera. The optimum TPC content was recorded at lower pressure of 80 bar as compared to 120 bar along with increasing the co-solvent concentration from 10 to $20 \%$ (w/w). Unlike the later findings, complete opposite effect of pressure was found on polyphenolic extraction in SFE [64,65], which may be due to the fact that they have used a single-step extraction method while Da Porto [63] used two-step extraction $\left(\mathrm{Sc}-\mathrm{CO}_{2}\right.$ and $\mathrm{Sc}-\mathrm{CO}_{2}+\mathrm{co}$-solvent) for removal of non-polar and polyphenolics, respectively from grape seeds. Removing non-polar compounds at first and increasing the co-solvent polarity, improve polyphenolic extraction yield under SFE [66]. Similarly, increasing the flow rate, prolong the contact time between solvent and extracted compounds, so the mass transfer increases. Comparative study between UAE, maceration and HAE was performed for polyphenolic extraction from Thymus serpyllum herb. UAE showed the highest TPC, followed by HAE and the maceration showed the lowest TPC [67].

The release of polyphenolics was also enhanced by the hydration of the cell wall, thus increasing their yield through facilitating the penetration of solvent, and thereby the efficiency of total polyphenols extraction and the release of soluble polyphenols from the plant cell vacuoles were enhanced [68]. As such, the polyphenolics extraction from Ulmus pumila barks was performed by using three enzymes as a mixture, which included cellulase $200 \mathrm{U} / \mathrm{g}$ sample, pectinase $20 \mathrm{U} / \mathrm{g}$ sample and $\beta$-glucosidase $16 \mathrm{U} / \mathrm{g}$ sample under enzyme assisted extraction (EAE) [69]. Increasing incubation period up to $90 \mathrm{~min}$ could increase the yield but caused a slight decrease of TPC. This may be because of possible degradation of the polyphenolic or may be due to conversion of polyphenols to new compounds.

Zhou et al. [69] also compared the optimum incubation time to obtain maximum TPC using EAE, UAE and conventional heated extraction (CHE), where the UAE needed just 50 min, while EAE and CHE needed 62 and $80 \mathrm{~min}$, respectively [69]. This was explained by Ramic et al. [70] who mentioned that the ultrasonic power brakes down the plant cell walls and thus aid the extraction of polyphenols [70]. But on the other hand, EAE showed the highest TPC, followed by UAE, then CHE. These results could be also attributed to the higher ability of the trienzyme mixture to hydrolyze the plant cell walls and crushing of the microstructure of plant cells promoting a more abundant release of the polyphenols bound in cell's content. Similar findings were obtained by Mushtaq et al. [71] when he tried a hydrolyzing complex of the cell wall of pomegranate peels which led to an enhanced recovery and liberation of polyphenols.

Another eco-friendly extraction technique of polyphenols is MAE, which can be considered as a powerful tool for extraction of natural compounds from plants. However, numbers of the papers are published with MAE of polyphenolics showed that MAE causes degradation of polyphenolics due to excessive heat $\left(>100^{\circ} \mathrm{C}\right)$ [72] and could be avoided by minimizing the temperature exposure during MAE [73-75]. Recently, special equipment was developed which allowed the microwave heating of plant material using a slot end coaxial antenna into a microwave applicator provided with an efficient cooling system [76]. The equipment aimed for achieving a high specific ab- sorption rate at low temperatures especially on applying low stirring rates where a non-uniform heating was obtained that could properly prevent degradation of the extracted natural products. The extracts obtained by this equipment from the leaves of sea buckthorn showed higher TPC and higher antioxidant power when compared to the extracts prepared at the same temperature profile and in the same extraction cell by conventional methods [76]. Also, a novel extraction method combining microwave and negative pressure was used for extraction of polyphenols from Pyrola calliantha using ionic solvent [29]. The extraction yield was found to be higher as compared with MAE and NPCE.

\subsubsection{Extraction of flavonoids}

Xie et al. [77] reported a novel use for MAE for the extraction of flavonoids (especially vitexin and isovitexin) from Crotalaria sessiliflora, a leguminous plant used in Chinese medicine for the treatment of many types of cancer and cardiovascular diseases [77]. They combined MAE with another emergent technology, aqueous two-phase extraction (ATPE), a method that allows the separation of target constituents and impurities with biphasic extraction and high selectivity [77]. MAE coupled with HPLC provides a one-step process for simultaneous extraction and purification of molecules of interest. Due to high water content, this method results in an increase in extraction yield $(355.3 \mu \mathrm{g} / \mathrm{g}$ for vitexin and 235.9 for isovitexin $\mu \mathrm{g} / \mathrm{g})$ and recovery $(94.14 \%-105.5 \%)$, and a lower environmental impact [77]. In the year 2017, the same research group developed a different method of flavonoid extraction from C. sessiliflora, combining MAE with cloud-point extraction, a novel extraction technique which splits plant extract constituents beyond their cloud-point temperature by the effects of a non-ionic surfactant. Thus, at the end of the process, hydrophobic molecules are present in the surfactant-rich phase, and hydrophilic molecules are suspended in the aqueous phase. Unlike the microwave-assisted aqueous two-phase extraction process, microwave-assisted cloud-point extraction is a two-step process characterized by higher selectivity and higher extraction yield $(601.4 \mu \mathrm{g} / \mathrm{g}$ for vitexin and 386.7 for isovitexin $\mu \mathrm{g} / \mathrm{g}$ ) [78].

PLE coupled with reversed-phase liquid chromatography (RP-LC-PDA) were used for the isolation and detection of phytoestrogenic isoflavones in the extract from the aerial part of Trifolium species. This study showed that PLE is found to be advantageous in term of sample preparation, low cost of reagent and higher yield of isoflavone aglycones and had good precision and accuracy compared to conventional extraction [79].

A study was done by Wang et al. [80] on subcritical extraction of flavonoids from the leaves of Moringa oleifera. The aim of the study was to find the optimum condition for large scale extraction of flavonoids using subcritical ethanol extraction method. The optimum conditions involved extraction temperature of $126.6^{\circ} \mathrm{C}$, and extraction time of $2.05 \mathrm{~h}$ using $70 \%$ ethanol. In order to obtain a yield of $2.06 \%$ of flavonoids, the subcritical extraction used only $4 \mathrm{~h}$, while the traditional ethanol reflux needed nearly half a day. This means that the traditional method spent twice as much energy as subcritical extraction.

$\mathrm{Xi}$ and Yan [81] optimized the conditions such as pressure, ethanol concentration, and solvent to solid ratio, temperature and extraction time for proper PSE extraction of flavonoids from Flos Sophorae and compared it with HRE. Yield of flavonoids was improved by increasing the pressure up to $450 \mathrm{MPa}$, after that any increase in the pressure caused a decrease in the yield of flavonoids. Therefore, $450 \mathrm{MPa}$ was optimum for extraction of flavonoids. These results could be explained by $\mathrm{Xi}$ and Luo [82], who found that increasing the pressure has positive effect on the solvent viscosity, diffusion and surface tension, thus increases solubility of the natural compounds, but further increase in the pressure can damage these 
compounds. $\mathrm{Xi}$ and Yan [81] had also shown that higher yield of flavonoids were recorded at higher ethanol concentration (up to $75 \%$ ), and any further increase in ethanol concentration beyond $75 \%$ will decrease the flavonoids yield. This may be due to that $75 \%$ aqueous ethanol represents the most suitable polarity for flavonoids extraction and also the presence of water increases the swelling index and contact surface area of plant material with the solvent $[83,84]$. The yield of flavonoids was also increased by increasing liquid to solid ratio up to $30 \mathrm{~mL} / \mathrm{g}$ but any further increase in this ratio didn't cause any improvement in the flavonoid yields. On comparing PSE with HRE using the optimum conditions, it was found that PSE yield $200 \pm 8.63 \mathrm{mg} /$ $\mathrm{g}$ of flavonoids in $5 \mathrm{~min}$ as compared to only $148 \pm 9.76 \mathrm{mg} / \mathrm{g}$ for $2 \mathrm{~h}$ under HRE. The higher efficiency of PSE could be attributed to the effect of high pressure that can cause cell disruption and reduction of particle size leading to increase in contact surface area and thus make better access of target compounds to solvent [82].

Another effective technique for flavonoids extraction is MAE. Blackcurrent mark has been extracted under homogenate-microwave-assisted extraction (H-MAE) for flavonol and anthocyanins [85]. Both, these compounds are unstable under neutral or alkaline conditions [86,87], therefore acidic solution was used for the extraction. Moreover, these compounds are sensitive to oxidation and thus different antioxidant were added to the extracting solvent. The extraction yield of both flavonols and anthocyanins, were found to be highest for tert-butylhydroquinone $(2180 \pm 96 \mu \mathrm{g} / \mathrm{g})$, followed by butylated hydroxytoluene $(2010 \pm 92 \mu \mathrm{g} / \mathrm{g})$ and hydroxyanisole $(1700 \pm 78 \mu \mathrm{g} / \mathrm{g})$. Similarly, the yield was increased with increasing homogenisation time from 1 to $3 \mathrm{~min}$, with further increase in time showed no significant result [85]. These high temperature extraction techniques may also cause compound degradation and thus need some alternative method for extraction of these compounds with higher extraction yield. As such, NPCE uses lower extraction temperature and the extraction yield of flavonoids was found to be higher as compared to UAE, MAE and HRE from pigeon pea [30].

\subsubsection{Extraction of anthocyanins}

The conventional solvent extraction of anthocyanins is solvent-wasting and time consuming, as well as low yield [88]. On the other hand, thermal extraction over an optimum period of time may cause the decomposition of anthocyanins and may also lead to the loss of bioactivity [89]. Using advanced extraction methods have advantages for anthocyanins extraction. For instance, in EAE of anthocyanins from freeze dried fruit samples of Prunus nepalensis, results indicated that the highest anthocyanin content was obtained with cellulase enzyme followed by pectinase [90]. Moreover, the rise in temperature up-to $40^{\circ} \mathrm{C}$ increases the anthocyanin yield, but further increase in temperature decreases the yield. Higher temperature might result in deactivation of the enzymes resulting in reduced catalytic activity [91]. In addition; higher temperature causes thermal degradation of anthocyanins [92]. Further, excess of water retards the enzymatic process due to the formation of an interface that prevents the solvent dispersion into the substrate $[93,94]$.

Recently, Feuereisen et al. [95] had introduced the PLE method for extraction of anthocyanins from Brazilian pepper fruits. For an effective extraction, it was necessary to get defatted the drupe grit by ASE (Accelerated Solvent Extraction) with petrol ether at $60^{\circ} \mathrm{C}$ for a static period of 6 min. Without defatting, diffusion of the solvent was hindered and the yield was decreased. Thereafter, the extraction of anthocyanins from exocarps was performed using PLE and the ideal conditions were determined experimentally to be $100^{\circ} \mathrm{C}$ for $10 \mathrm{~min}$ static time and the optimum concentration of ethanol and acetic acid were $54.5 \%$ and $5 \%$, respectively. For exhaustive extraction of anthocyanins from exocarps two cycles were applied each continuing for
10 min. A method based on PLE combined with UAE has been developed for the recovery of anthocyanins from residues of Rubus fruticosus, Vaccinium myrtillus and Eugenia brasiliensis. The extraction efficiency for anthocyanins increases on applying UAE in combination with PLE as compared to PLE alone [96]. These advanced extraction techniques save time, solvent and thus are economically viable. For instance, only $\sim 72 \%$ of silymarin was extracted in $5 \mathrm{~h}$ of soxhlet extraction as compared to PLE which was operated at $125^{\circ} \mathrm{C}$ for $10 \mathrm{~min}$ [97].

UAE has been extensively used to extract anthocyanins from plant materials $[98,99]$. In order to obtain a maximum yield of anthocyanins, it is important to specify the optimum extraction conditions for UAE. For extraction of two or more compounds, having different physicochemical properties different approach needs to be followed. For instance, Espada-Bellido et al. [100] used the UAE method for the extraction of anthocyanins and phenolics from the Morus nigra pulps under different extraction conditions. The extraction was performed by using an ultrasonic system inside a temperature controlled water bath. Under this, the optimum extraction condition for both anthocyanins and phenolics were found to be different. For instance, $76 \%$ methanol having $\mathrm{pH} 3$ was used for optimum anthocyanin extraction, while only $61 \%$ methanol $(\mathrm{pH} 7)$ was used for phenolic extraction. However, a higher temperature of $64^{\circ} \mathrm{C}$ was used for phenolic as compared to $48^{\circ} \mathrm{C}$ for anthocyanin extraction. Anthocyanins are sensitive to temperature and thus minimum extraction temperature is required for their extraction. In addition, the $\mathrm{pH}$ sensitive extraction of anthocyanins requires acidic $\mathrm{pH}$ for stabilization [100].

Extraction of anthocyanins is sensitive toother process factors, as attachment to sugar molecules and the presence of ions [101,102]. For better extraction efficiency these factors need to be optimized. As such, Farzaneh and Carvalho [103], used response surface methodology (RSM) to study MAE parameters such as microwave irradiation power, irradiation time and solvent/sample proportion to optimize the method for anthocyanin extraction from Lavandula pedunculata fresh plants. Wu et al. [104] in a research article on anthocyanin extraction from powdered blueberry compared MAE with Hot Reflux Extraction (HRE) to investigate the differences on anthocyanin degradation kinetics, at the same process temperature of $30^{\circ} \mathrm{C}-70^{\circ} \mathrm{C}$. They found that MAE, unlike HRE, leads to a better extraction yield and a lower degradation rate [69]. In the same year, Li et al. [85] utilized a Homogenate-MAE to extract anthocyanins from blackcurrant. In optimal conditions, which consisted of $\mathrm{pH} 2.5$, a liquid-solid ratio of $28.3 \mathrm{~mL} / \mathrm{g}$, a microwave irradiation power of $551 \mathrm{~W}$, a process time of $16.4 \mathrm{~min}$, and using $60 \%$ ethanol as solvent; the extraction yield of anthocyanins was found to be $473.7 \mu \mathrm{g} / \mathrm{g}$ of fruit homogenate, avoiding degradation or isomerization [85]. In a research article about the extraction of anthocyanins from purple sweet potatoes by three different methods, the authors concluded that the best extraction yield was obtained with MAE ( $80 \mathrm{~W}$ for $300 \mathrm{~s}$, using ethanol-tartaric acid solvent) compared to UAE and maceration [105]. Similarly, in the same year, ASE, UAE and conventional extraction were compared for anthocyanin extraction from purple sweet potato, and it was found that ASE was superior as compared to other techniques. However, for flavonoids conventional extraction worked better than UAE and ASE [105]. Food waste such as by-products of the wine industry and grape juice are a rich source of anthocyanins and MAE has been applied to extract anthocyanins from them [102].

\subsubsection{Extraction of alkaloids}

Because of the promising biological applications of alkaloids, there is continuous research for the development of new extraction and purification techniques of alkaloids in recent years. Many researchers have reported the comparison between the traditional methods of extraction such as infusion, pressing and solvent extraction 
and the novel techniques, such as MAE and SFE. The choice of the extraction method highly affects the yield and the composition of the extract as well as its alkaloid content. Modern techniques such as SFE using supercritical $\mathrm{CO}_{2}$ and propylene glycol as co-solvent, and MAE had shown certain selectivity towards specific alkaloids, such as coptisine [106]. The use of polar co-solvents such as water and alcohols in SFE of alkaloids always shows higher yields than using pure $\mathrm{CO}_{2}$, this may be due to the fact that increasing solvent polarity can increase its diffusion properties. On the other hand, pure $\mathrm{CO}_{2}$ produces lower yields than any other solvent extraction method. Also, the use of the suitable solvent mixture may have a positive effect on the selective extraction of certain compounds or a class of compounds, which will surely affect the biological activity of the extracts [107]. For example, the yield of hyoscyamine and scopolamine was markedly increased by the use of a co-solvent consisting of a mixture of methanol and diethylamine $(10 \% \mathrm{v} / \mathrm{v})$ in the SFE of Scopolia japon$i c a$ at $333 \mathrm{~K}$ and $34 \mathrm{MPa}$ [108], the authors explained that by the presence of hyoscyamine and scopolamine as hydrochloride salts in the plant, such salts are insoluble in $\mathrm{Sc}-\mathrm{CO}_{2}$ due to its acidity and low polarity. Moreover, the use of a basifying agent such as diethylamine (DEA: $10 \%, \mathrm{v} / \mathrm{v})$ and a polar co-solvent like water $(1 \%, \mathrm{v} / \mathrm{v})$ in SFE could increase the yield of extracting isoquinoline alkaloids by about $50 \%$ of the total extract after $2 \mathrm{~h}$ of extraction when operated at $343 \mathrm{~K}$ and $20 \mathrm{MPa}$ [109].

A study was done by Gañán et al. [107] on the SFE of aerial and terrestrial parts of Chelidonium majus for extraction of alkaloids and other compounds [110]. The procedure involved two steps fractionation, first SFE using pure $\mathrm{Sc}-\mathrm{CO}_{2}$ and the second ESE (enhanced solvent extraction) step using $\mathrm{Sc}-\mathrm{CO}_{2}$ and a basified co-solvent mixture composed of isopropanol or ethanol and DEA in a ratio of 9:1 $(v / v)$. SFE was compared to Soxhlet extraction using ethanol and low pressure solvent extraction with water (LPSE). Using $\mathrm{Sc}-\mathrm{CO}_{2} /$ isopropanol/DEA mixture (ESE step) showed the highest alkaloids yield $(15.8 \mathrm{mg} / \mathrm{g}$ raw material) and highest alkaloid selectivity (508 mg alkaloids/g of extract) from the terrestrial parts of the C. majus, this was obtained at a density of $881 \mathrm{~kg} / \mathrm{m}^{3}(328 \mathrm{~K} / 35 \mathrm{MPa})$. The use of new extraction techniques here showed an increase in the alkaloid yields by $8-10$ times than that reported before using the traditional extraction methods [111,112]. SFE technique is highly selective for alkaloids, the solubility of alkaloids in $\mathrm{Sc}-\mathrm{CO}_{2}$ increases on increasing the solvent density up to $813-850 \mathrm{~kg} / \mathrm{m}^{3}$, and after that it may decrease. The use of basified alcohol mixtures as co-solvents enhances alkaloid yield from plant materials [110,113].

Traditionally alkaloid extraction was achieved using non-polar or organic solvents under alkaline conditions [114-119] or using polar solvents under acidic conditions [120,121]. Various techniques are used for clean-up of the alkaloids such as liquid-liquid extraction [117] and solid phase extraction (SPE) or dispersive SPE (dSPE) using various materials and solvents. Mueller et al. $[118,119]$ used SPE employing alkaline alumina cartridges, while Mohamed et al. [122] used octadecyl (C18) endcapped silica, and Koeppen et al. [123] and Malysheva et al. [121] employed strong cation exchange (SCX). Recently, Oellig and Schwack [124] developed a fast screening method for the quantification of the total ergot alkaloids in rye using planar SPE. This method showed high efficiency by concentrating target compound in a single zone, which can be easily separated from rest of the matrix components $[125,126]$. The method of Oellig and Schwack [124] used the method of Mohamed et al. [122] as a guide for sample extraction but modifying the use of $10 \mathrm{mM}$ ammonium acetate buffer by $0.5 \mathrm{M}$, which produced more stable $\mathrm{pH}$ during extraction of ergot alkaloids and increases extraction yield. Another technique was developed in recent years for the determination of glycol alkaloids in potatoes based on MAE, more efficient and faster than common methods [127]. The authors found a 37\% improvement of recovery efficiency $(19.92 \mathrm{mg} / \mathrm{kg})$ under optimal conditions (100 W, $10 \mathrm{~min}$, methanol solvent), when compared to traditional solid/liquid extraction methods $(12.51 \mathrm{mg} / \mathrm{kg})$ [124].

Alkaloids can also be efficiently extracted with PEF and UAE technology. Bai et al. [128] investigated alkaloid extraction yields of Aconitum coreanum under different extraction methods, starting from plant roots [128]. The authors found that PEF extraction and UAE are the best methods to improve the extraction yield of alkaloids $(36.25 \%$ and $40.50 \%$, respectively), and of these, PEF extraction has obtained better levels of guanfu base A, a diterpene alkaloid with anti-arrhythmic activity, in the A. coreanum extract [128]. Another environment friendly method NPCE was introduced for the extraction of alkaloids (vindoline, catharanthine, vincristine and vinblastine) from Catharanthus roseus leaves [31]. The extraction yield of these compounds were compared with UAE and found to be similar, however, the yield was found higher as compared to maceration and HRE.

\subsubsection{Extraction of polysaccharides}

A wide range of recent investigations are reported in the literature regarding MAE of polysaccharides from plant sources. This fact is likely due to a number of problems with traditional methods for polysaccharides extraction. For instance, higher process temperature and extraction time can depolymerize and de-esterify protopectin, resulting in functional property loss. Furthermore, there are many problems related to the viscosity of pectin. Solvent $\mathrm{pH}$ value represents another problem, as pectin degrades more quickly under neutral or alkaline conditions, so solvent $\mathrm{pH}$ values ranging from 1 to 3 have been preferred. MAE offers a reduction in the solvent volume required, and an improvement of the quali-quantitative characteristics of pectins $[129,130]$.

A newmethod was developed for extracting water soluble polysaccharides such as arabinose, galacturonic acid, galactose, etc. from Gentiana scabra using microwave-assisted aqueous two-phase extraction [131]. Traditional extraction of these polysaccharides, through methods such as hydrolysis and maceration, has struggled with lengthy extraction times, high solvent consumption rates, low extraction yield, high levels of impurities and the degradation of unstable molecules. Traditional MAE has also been evaluated, but this has issues with impurities in the extract, resulting in complex post-extraction separation procedures and thus microwave-assisted aqueous two-phase extraction was used. The results from HPLC analysis of the extract showed that, under optimized condition, the purity of water-soluble polysaccharides was $78.19 \pm 0.42 \%$ and the extraction yield was $15.97 \pm 0.32 \%$ for the top phase and $16.55 \pm 0.13 \%$ for the bottom phase, indicating that microwave-assisted aqueous two-phase extraction intensifies the extraction process and improves the purification process when compared with basic MAE or other common extraction techniques [131].

Chicory roots (Cichorium intybus), characterized by high inulin content $(14.9-18.3 \%)$, is considered to be the elective matrix for industrial inulin extraction. Inulin is used in both food and health products, as a prebiotic, appetite regulator and as a protective agent for the intestinal tract [132]. For inulin extraction, PEF has been found to be the most efficient extraction method among other non-conventional extraction techniques, such as UAE, EAE, MAE and SFE [133]. As far as PEF inulin extraction is concerned, inulin extraction yield is better than that of the conventional extraction method at $80^{\circ} \mathrm{C}$, with the improved yield of $\mathrm{PEF}$ methods running at lower temperatures ranging from $30^{\circ} \mathrm{C}$ to $60^{\circ} \mathrm{C}$ [134]. Authors concluded that the reduction of the PEF process temperature offsets the higher energy consumption of the method itself, giving rise to net savings [134]. In 2013, the same research group confirmed conclusions obtained in the previous study and added an ultrafiltration system to the PEF system, obtaining further purification of the juice [135]. More recently, in 
2015, Zhu et al. [136] continuing their research on possible alternatives for inulin extraction, coupled PEF treatment and ohmic heating to obtain faster permeabilisation of the chicory tissue [136].

Seaweed is also a good source of polysaccharides. Recently, $\mathrm{Wu}$ et al. [137] described EAE extraction using $\alpha$-amylase from Thermococcus sp. HJ21 of polysaccharides from Gracilaria lemaneiformis. The extraction conditions were $95^{\circ} \mathrm{C}, \mathrm{pH} 5,40 \mathrm{~min}$, and enzyme amount of $6000 \mathrm{U} / \mathrm{g}$, obtaining a polysaccharide extraction yield of $49.15 \%$. Moreover, the extract demonstrated strong hydroxyl radical scavenging activity [137].

\subsubsection{Extraction of carotenoids and saponins}

Carotenoids are broadly distributed in plant-derived foods, and constitute the main dietary sources of Vitamin A. Further, intake of carotenoids is associated with the reduction of several health problems as cancer, age-related macular degeneration, and cardiovascular diseases [138], among others, Roohinejad et al. [139] used an oil-in-water microemulsion in combination with PEF treatment to avoid the use of organic solvents, since previous findings demonstrated the ability of microemulsion to protect carotenoids and to improve the selective extraction of various bioactive molecules. Under optimum conditions (extraction time $49.4 \mathrm{~min}$, temperature $52.2^{\circ} \mathrm{C}$, field strength $0.6 \mathrm{kV} /$ $\mathrm{cm}$, pulse duration $20 \mu \mathrm{s}$, treatment time $3 \mathrm{~ms}$ ), the extraction yielded a microemulsion with $\beta$-carotene concentration as $19.6 \mu \mathrm{g} / \mathrm{g}$, which could be used as a promising vehicle for fortified foods and food supplements [139]. In addition, the use of MAE, UAE, and EAE, have been used for the recovery of different carotenoids from tomato processing by-products [140].

Enzymatic treatments have long been used in fruit juice production, to increase the quality and quantity of extract. In recent years, EAE has been more extensively applied to plant matrices for improving the yield of compounds of interest [90]. As such, growing demand for green food additives has given rise to EAE applications in the extraction of natural colorants from plants. For instance, EAE has been used to extract a carotenoid-rich fraction from red chili pepper (Capsicum annuum) with the highest carotenoid content of $30.37 \mathrm{mg} / 100 \mathrm{~g}$ fresh weight [141]. The enzyme mix used consisted of pectinase (from Aspergillus niger), viscozyme L (from Aspergillus aculeatus), and cellulase (from Trichoderma reesei), with an enzyme/mash ratio of 0.10 , $0.20,0.30 \%$. Results indicate that the highest dose of viscozyme L gave the best recovery yield, not only for carotenoids, but also for total phenolic compounds and flavonoids [137].

Another study aimed at the extraction of plant secondary metabolites was conducted by $\mathrm{Lu}$ et al. [142], focused on ginsenoside saponins from ginseng roots (Panax ginseng). Conventional methodologies, such as hot reflux extraction, could generate methyl derivatives through the employment of methanol solvent in the extraction of the saponins. The results indicate that pulsed electric field combined with a $\beta$-glucosidase treatment has a better ginsenoside extraction yield $(38.15 \pm 1.84 \mathrm{mg} / \mathrm{g})$, compared to hot reflux extraction $(31.98 \pm 1.51 \mathrm{mg} / \mathrm{g})$, microwave-assisted extraction $(23.24 \pm 1.10 \mathrm{mg} /$ $\mathrm{g})$, and ultrasonic-assisted extraction $(27.53 \pm 1.66 \mathrm{mg} / \mathrm{g})[142]$.

\subsection{Strategies for designing extraction process}

For efficient extraction outcomes, not only the type of extraction methods used but also the factor consideration and their linear, quadratic and interactive effects are of great value for understanding their effect on responses and to maximize the compound yield while minimizing the energy loss and solvent consumption which ultimately add to the economic value. Various factors based on the solvents, raw materials and extraction method used need to be considered for opti- mum extraction design (Table 1) and few of them are discussed below.

\subsubsection{Solvent selection}

Selection of solvent should be in accordance with the chemical nature of the targeted compounds. For instance; polar solvents such as ethanol, methanol, ethylacetate, etc. are used for extraction of hydrophilic components in plants, whereas non-polar (or apolar) solvents, i.e. hexane, ether, petroleum ether, etc. are preferred for extraction of lipophilic secondary metabolites [143]. Although water is the cheapest and non-toxic solvent, however it is a good medium for growth of mold and bacteria. Besides, it may cause hydrolysis or decomposition of plant metabolites and requires a high temperature to evaporate from extracts. Ethanol and methanol are beneficial solvents for extracting alkaloids, flavonoids, terpenes, glycosides, and coloring compounds, but they are no able to dissolve polysaccharides, tannins, gums, and waxes and also these are inflammable. When selecting a solvent for extraction, the following parameters should be taken into consideration such as solvent power, boiling point, reactivity, viscosity, recovery, vapor pressure, safety, toxicity and cost. Selection of solvent is not only depending on the nature of compound being extracted, but also on the extraction process and its end use. For instance, in case of MAE, in order to choose the best solvent, the solubility of desired molecules and the dielectric properties of the solvent must be considered. Non-polar solvents are usually characterized by low dielectric constants, and therefore are not suitable for microwave extraction, while polar solvents are widely used due to high dielectric constants which permit a better absorption of microwaves. Nevertheless, there is a contrasting opinion, called "broken cell-wall theory", which supports microwave transparent solvents (of the non-

\section{Table 1}

Factor consideration under different extraction techniques.

\begin{tabular}{|c|c|c|c|c|}
\hline $\begin{array}{l}\text { S. } \\
\text { No. }\end{array}$ & $\begin{array}{l}\text { Extraction } \\
\text { Method }\end{array}$ & Factor Consideration & & \\
\hline & & Instrumentation & Solvent & $\begin{array}{l}\text { Plant } \\
\text { material }\end{array}$ \\
\hline 1 & UAE & $\begin{array}{l}\text { Ultrasonic frequency, } \\
\text { power, sonication } \\
\text { time and temperature }\end{array}$ & $\begin{array}{l}\text { Solvent type, } \\
\text { polarity, solubility, } \\
\text { toxicity, } \\
\text { concentration, } \\
\text { volume and pH }\end{array}$ & $\begin{array}{l}\text { Particle size, } \\
\text { feed to } \\
\text { solvent ratio } \\
\text { and } \\
\text { moisture } \\
\text { content }\end{array}$ \\
\hline 2 & MAE & $\begin{array}{l}\text { Microwave power, } \\
\text { irradiation time and } \\
\text { temperature }\end{array}$ & $\begin{array}{l}\text { Solvent type, } \\
\text { polarity, solubility, } \\
\text { toxicity, } \\
\text { concentration, } \\
\text { volume, } \mathrm{pH} \text { and } \\
\text { dissipation factor }\end{array}$ & \\
\hline 3 & SFE & $\begin{array}{l}\text { Temperature, pressure } \\
\text { and flow rate }\end{array}$ & $\begin{array}{l}\text { Solvent type, } \\
\text { polarity, solubility, } \\
\text { toxicity, } \\
\text { concentration, } \\
\text { volume, pH and } \\
\text { co-solvent type and } \\
\text { concentration }\end{array}$ & \\
\hline 4 & PLE & $\begin{array}{l}\text { Temperature, time, } \\
\text { extraction mode } \\
\text { (dynamic/static) and } \\
\text { pressure }\end{array}$ & $\begin{array}{l}\text { Solvent type, } \\
\text { polarity, solubility, } \\
\text { toxicity, } \\
\text { concentration, } \\
\text { volume and pH }\end{array}$ & \\
\hline 5 & PEF & $\begin{array}{l}\text { Electric field intensity, } \\
\text { pulse type and } \\
\text { treatment time }\end{array}$ & $\begin{array}{l}\text { Solvent type, } \\
\text { polarity, solubility, } \\
\text { toxicity, } \\
\text { concentration, } \\
\text { volume and pH }\end{array}$ & \\
\hline 6 & EAE & $\begin{array}{l}\text { Extraction time and } \\
\text { temperature }\end{array}$ & $\begin{array}{l}\text { Enzyme type and } \\
\text { concentration }\end{array}$ & \\
\hline
\end{tabular}


polar variety) for use in MAE [144]. Despite these differences in opinion, both polar and non-polar solvents have successfully been used in microwave extraction. In fact, direct heating of the plant microwave-absorbing matrix can be applied to extract thermo-sensitive compounds, which liberates target compounds to the surrounding non-polar solvent, colder than the polar solvent. In other cases, polar solvents can be the best choice, as a polar solvent brought to boiling point can better extract those compounds which are not damaged by high temperatures. Solvent mixtures can be used to modulate the selectivity of extraction, and any dried plant tissues must be re-hydrated to increase their dielectric susceptibility and provide a better yield.

Alternative solvents: There is a growing interest for using green extraction solvent, which is devoted to the environmental friendly nature and can meet both industrial and economical demand [145]. For this reason, the use of natural deep eutectic solvents (NADES) as a green alternative to conventional solvents has been originated [146]. NADES present a new generation of liquid salts, which involve the use of cheap and readily available components, such as choline chloride which is a non-toxic quaternary ammonium salt together with natural uncharged compounds such as alcohols, amines, vitamins, carboxylic acids and sugars which are hydrogen-bond donors. Those compounds provide a 'green profile' and have good prospects for wider use in the field of green technologies [147]. For instance, ChMa (choline chloride plus malic acid) could be selected as the most promising solvent for anthocyanins extraction from wine lees, as compared to conventional solvents [148]. Deep eutectic solvents (DESs) were also used for extraction of natural compounds which are composed of low-transition temperature mixtures (LTTMs) consisting of both hydrogen bond donor (HBD) and hydrogen bond acceptor (HBA) bioorganic molecules [149]. These were found to increase the extraction yield of compounds [150].

Aqueous solutions of cyclodextrins (CDs), a group of water-soluble cyclic oligosaccharides that have truncated cone shape possessing hydrophobic cavity [151], is another alternative green solvent as it forms an inclusion complex with non-polar compounds which are named guests by receiving them in their cavities [152]. Cyclodextrins enhanced the extraction of polyphenols as the radical scavenging activity of the deionized water extract was $75 \%$ while $\beta-C D$ and $\mathrm{HP}-\beta$-CD showed $83 \%$ and $86 \%$, respectively [153]. $\mathrm{CO}_{2}$ is also used as an alternative solvent, but its use is limited, as it requires specialized instrumentation for operations. In SFE the $\mathrm{CO}_{2}$ is commonly used as supercritical fluid and has several advantages such as being inert, non-toxic enables extraction at low temperature and pressure. However, $\mathrm{CO}_{2}$ has the drawback of being weak solvent in extracting highly polar compounds, including phenolic compounds, and this is because it is a nonpolar and lipophilic solvent [154]. This drawback could be overcome by using a co-solvent, such as ethanol-water mixtures which found to be very effective in extracting anthocyanins from elderberry fruits and catechins from tea leaves $[155,156]$. On the other hands, ionic liquids (ILs) were used as green solvent and were employed in sample pretreatment techniques, like liquid-liquid extraction [157,158], headspace solid-phase microextraction [159-161] and aqueous two-phase system extraction [162,163]. On comparing the performance of IL (sodium chloride) with that of acidic water extraction and organic solvent extraction under UAE and HRE, the extraction efficiency of HRE was comparatively lower than that of UAE, and cost more time and energy $\left(100^{\circ} \mathrm{C}\right.$ and $2 \mathrm{~h}$ for aqueous solution). In case of UAE, acidic water was the most common and inexpensive solvent, but its average extraction efficiency of alkaloids is only $67.13 \%$. Sodium chloride was better solvent as the addition of salt enhanced the process of ion exchange that may make it easier for alkaloids to diffuse into the liquid phase. The results indicated that, comparing with the regular solvents and techniques, the proposed ap- proach turned out to be with higher extraction efficiency and shorter extraction time [164].

\subsubsection{Particle size and its shape}

Another important factor to improve the extraction recovery rate is plant particle size, which must be very small (ranging from $100 \mu \mathrm{m}$ to $2 \mathrm{~mm}$ ) to increase the contact surface area of sample with solvent [48]. Moreover, the particle size depends on the grinding efficiency or technique used, and thus affects extraction effeiciency [7]. For example, when particle size of clove buds reaches up to $0.1-0.5 \mathrm{~mm}$, eugenol is extracted $60 \%$ more as compared to using entire clove buds [165]. When the particle size is smaller, it provides more surface area for the solvent to penetrate, for cell disruption and mass transfer, thereby improving extraction [166]. As detailed by Vinatoru et al. [7], the shape of the vegetal particle is also important. The irregular shape of the particle after suspended in the solvent becomes more rounded and smoother. The particle is surrounded by solvent stagnant layer and diffusion of plant components starts, which depends on the type of solvent and extraction method.

\subsubsection{Drying condition}

Moisture content in the plant sample played crucial role in determining the final concentration of the compound and/or extract yield. Various drying techniques have been frequently used during extraction process of compounds, such as, sundrying, shade drying, air drying, oven drying, microwave drying and freez drying. Proper drying of the sample not only provide better yield but also improve the self life, reduce microbial growth and enzymatic activity, thus improved the storage capacity of the plant sample [167]. Various studies have been conducted on finding the suitable drying method based on the plant sample and compound of interest. As such, shiitake (Lentinus edodes) mushroom have been studied for amino acid and sulfur compounds concentration under hot air, vacuum, microwave and microwave vacuum drying conditions [168]. Among these microwave vacuum drying method was found to be superior in maintaining amino acid concentration and also in improving nutrient content and color attributes. In another study, Helicteres hirsute stem was processed for extraction of polyphenolic content and antioxidant activity under different drying conditions (hot air, low temperature air, infrared and vacuum drying). Hot air drying at $80^{\circ} \mathrm{C}$ was found to be best in extracting polyphenolics with significantly higher yield as compared to other drying methods [169]. However, no single drying method is universally accepted for various plant material or bioactive compound. For instance, for higher yield of polyphenols and antioxidant activity, infrared drying at $30^{\circ} \mathrm{C}$ was found best for Phyllanthus amerus whole plant [170]. Drying will also affect the specific bioactive compound concentration from a single plant sample. For instance, pomegranate peel was dried using freez and oven drying. The yield of punicalin was found higher with oven drying at $60^{\circ} \mathrm{C}$, however, freez drying results in higher catechin and epicatechin concentration. Also, freez drying results in higher total phenol, tannins and flavonoid concentration. Moreover, oven dried at $40^{\circ} \mathrm{C}$ results in better yield of Vitamin $\mathrm{C}$ as compared to other drying conditions [171]. Botanical extraction were generally used either fresh or dried sample. Variation in bioactive compounds concentration between fresh and dried sample have been reported. For instance, gingerol content was found to be reduced during drying as compared to the free sample of Ginger using SFE [172].

\subsubsection{Extraction technique}

The extraction yield not only depends on the raw material and solvent characteristics but also the type of extraction method used and its process factors that govern the quality and quantity of the compound being extracted. Depending on the type of compound, matrices 
(plant part), economic value, availability and its uses, extraction method is being selected. E Silva et al. [173] reported that the best extraction of fatty acids such as myristic, palmitic, stearic, oleic, and erucic acids was achieved with UAE with water for three cycles, using ethanol-chloroform-water- $\mathrm{Na}_{2} \mathrm{SO}_{4}$ and ethanol as solvents. For phytosterol extraction, a hyphenated technique of dual ultrasound-assisted dispersive liquid-liquid microextraction combined with microwave-assisted derivatization, has been recently demonstrated to be very efficient [174]. On the other hand, MAE was also found to be superior to traditional extraction methods in terms of better yield of polyphenol extraction [175,176]. Consistently, microwave-assisted hydrodistillation (MAHD) and solvent-free microwave extraction (SFME) were reported to be significantly advantageous over the conventional hydrodistillation for essential oils in many studies [177,178]. Besides, Dai et al. [179] displayed that MAE was superior in comparison to room temperature extraction, reflux temperature extraction as well as UAE in extracting aromatic components from peppermint (Mentha piperita L.) leaves. The instrument set-up is also important in determining the extraction efficiency and also to make sure its optimum utilization. For instance, for proper extraction under UAE, the position of extraction vessel needs to be considered to obtain maximum cavitation. Considering all these factors and its levels for optimization of extraction conditions is a tedious task, in which not only the number of experimental run increases but also the interactive effect cannot be determined. To overcome from these limitations of univariate analysis (one factor at a time), multivariate analysis was considered for optimization. Various statistical models and design such as, differential evolution technique (DET), response surface methodology (RSM) and neural networks (NN) have been frequently used in botanical extraction and few of them are discussed below.

\subsubsection{Response surface methodology (RSM)}

RSM is a statistical method which uses multifactorial approach for optimization of complex processes [180]. It gives a free space wherein the experimental terms were defined based on the response value and the level of each factor can be adjusted according to the requirement of the experiment (Supplementary Fig. 1). The factor terms are known as independent variables and the responses are defined as dependent variables (i.e. depend on the independent variables).

For performing systematical/effective botanicals extraction, various steps need to be taken as shown in Fig. 3. The first step is to

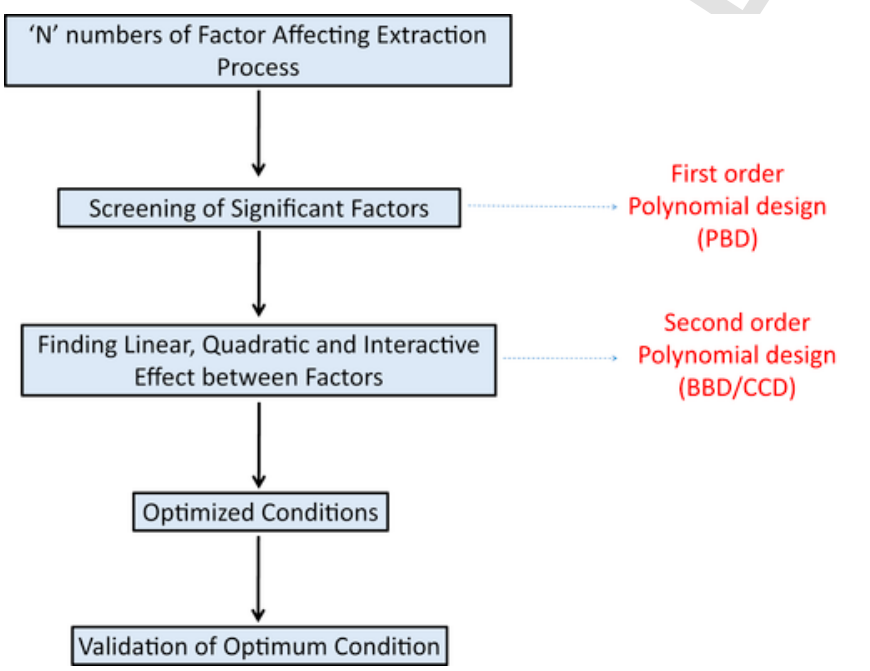

Fig. 3. Systematical design of extraction process for better results. screen all the independent variables which directly influence the dependent variables of choice. The screening is based on the linear effect and follows first order equation as:

$\mathrm{Y}=\beta 0+\sum \beta \mathrm{iXi}$

$\mathrm{i}=1$

where, $\beta_{0}$ is a constant term, $\beta_{\mathrm{i}}$ is coefficient of the linear parameters, $\mathrm{X}_{\mathrm{i}}$ represent the variables. Here the interactive effect is not considered. Plackett-Burman design (PBD) used first order equation to screen factors.

After selecting significant factors, the second step is to define the level of each significant factor and select the possible design for second order model (Fig. 4). Second order model tests factor levels at three levels (lower, middle and higher; $-1,0,1$ ) and followed equation as:

$$
Y=\beta_{0}+\sum_{i=1}^{k} \beta_{i} X_{i}+\sum_{i=1}^{k} \beta_{i i} X_{i}^{2}+\sum_{i=1}^{k} \sum_{j=i+1}^{k-1} \beta_{i j} X_{i j}
$$

where, $\mathrm{Y}$ is the response variable, $\beta_{0}$ is the constant, $\beta_{\mathrm{i}}$ is the linear regression coefficient, $\beta_{\mathrm{ii}}$ is the quadratic coefficient, $\beta_{\mathrm{ij}}$ is the interaction coefficient, $\mathrm{X}_{\mathrm{i}}, \mathrm{X}_{\mathrm{i}}^{2}$ and $\mathrm{X}_{\mathrm{ij}}$ is the linear, quadratic and interactive terms.

Based on the first order model, the selection of second-order model depends on regression coefficient of individual factors. Two types of models are generally used and discussed below:

\section{(a) Central Composite Design (CCD)}

CCD tested factor levels at extreme (higher or lower) and also giving options to test factors at a distance ' $\alpha$ ' from its center (Supplementary Fig. 2a). Each factor can be varied over 3 or 5 levels includes axial, factorial and central points. Here the experimental run was in a combination of factor levels consist of at least one experiment at higher and one experiment at lower level of each factors. CCD model will be selected if PBD model showed all significant factors having negative/positive regression coefficient values. Extraction of various compounds has been successfully optimized using this model (Table 2).

\section{(b) Box-Behnken Design (BBD)}

For BBD model factor levels were varied over 3 levels and also lesser experimental work is required as compared to CCD. The BBD design experimental runs will allow to test factors at least one at center point (0) (Supplementary Fig. 2b), hence selected for model wherein the regression coefficient value of all factors in first order model does not come either positive or negative. Various extraction optimization models used these second order design either directly or after screening factors (Table 2).

\subsection{Selection between good and excellent}

The traditional solvent extraction methods which were applied for extracting natural bioactive compounds have many limitations, for example they need prolonged working times, being exhausting procedures, using hazardous solvents and the obtained extracts have low yields. There is continuous need for improving extraction techniques through finding non-conventional extraction methods that achieve higher extraction efficiency at low temperature, short extraction time and reduced solvent and energy consumption. However, these techniques have limitations in terms of higher cost of operation, compound degradation, and large-scale operations, besides many others. In general, selection of extraction methods is mainly depending on 


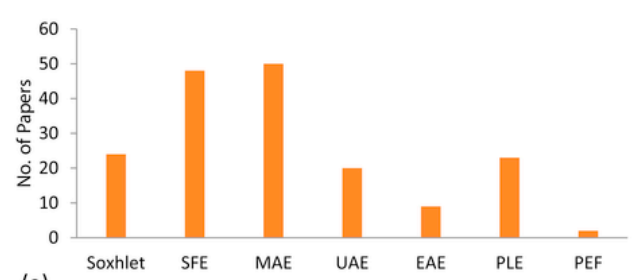

(a)

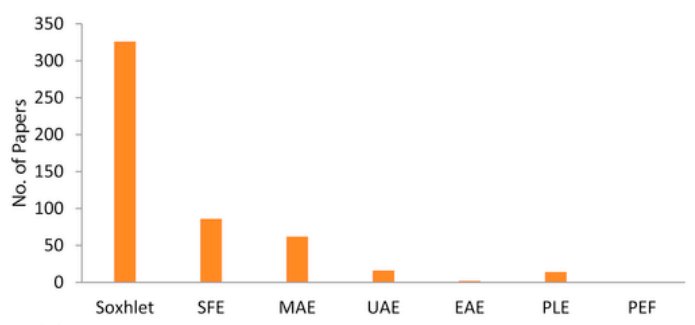

(c)

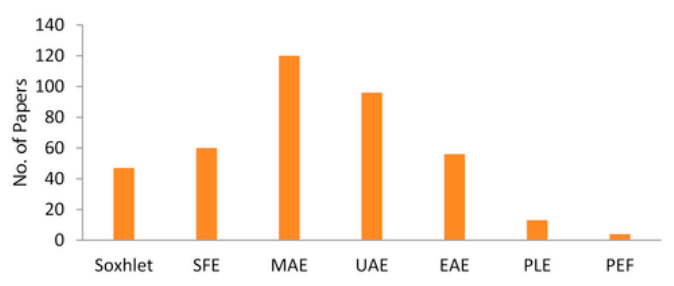

(e)

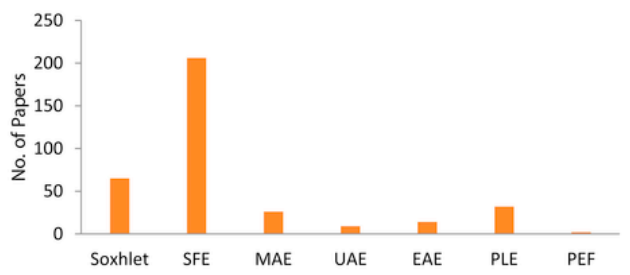

(g)

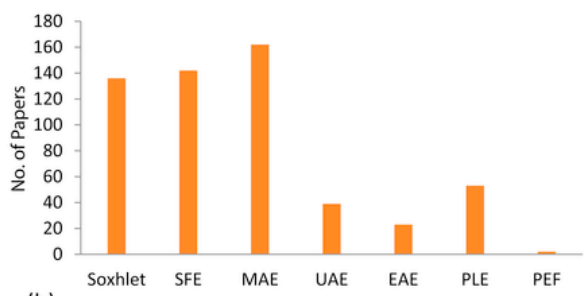

(b)

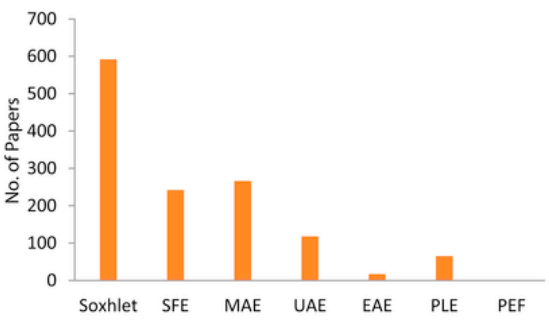

(d)

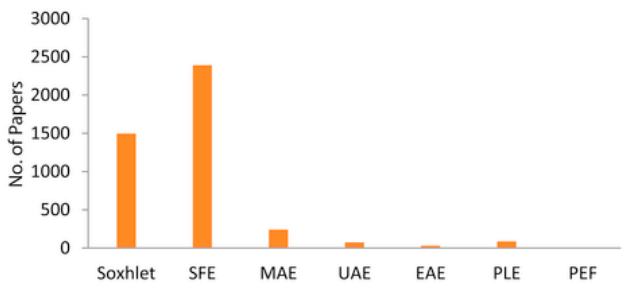

(f)

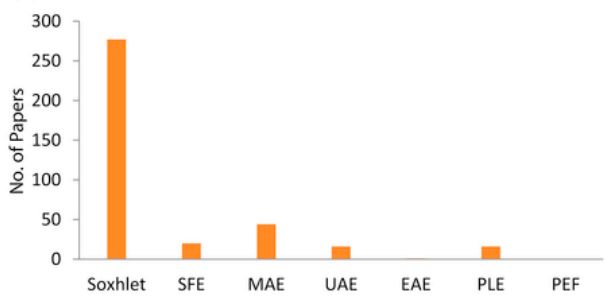

(h)

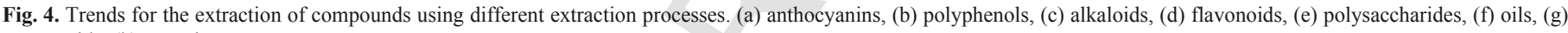
carotenoids, (h) saponins.

many factors, such as-physicochemical properties of compound and solvent, economical value of compound, environmental concern, etc. Moreover, there is no such extraction technique that has all the advantages without limitations. The comparison between extraction techniques $w$. r.t different parameters are shown in Table 3 and are discussed below.

In comparison to conventional extraction methods, the advanced extraction methods provide a shorter process time and greater efficiency. Also, it has been reported that the combined effect of different factors such as temperature along with ultrasonication is much more effective than using a single factor alone [181]. However, these techniques not only appear to be advantageous over conventional, but also sometimes induce degradation of compounds. For instance, ultrasonication produces reactive oxygen species during cavitation and results in degradation of the compounds. As such, the degradation of compounds under UAE is largely dependent on the presence of hydroxyl ketone and unsaturated double bonds [10], which are sensitive to free radical reactions under UAE, thus affecting stability. Higher number of hydroxyl group present in a compound accelerates degradation while glycosylation and presence of sugar promote recovery of compounds under UAE $[9,182]$. On the other hand, MAE has the advantage of providing homogenous heating. For instance, MAE re- duces the extraction time up-to $75-80 \%$, saves energy up-to $25-50 \%$, decreases waste and reduces footprint up-to $50-90 \%$ and many others [183]. However, MAE conditions are not compatible with the extraction of thermolabile compounds, and so vacuum microwave extraction was recently developed to provide a microwave-assisted extraction method with a lower reactor temperature. In 2012, Xiao et al. [184] used MAE in a low temperature vacuo environment to extract thermo-sensitive and oxygen-sensitive compounds: vitamin $\mathrm{C}$, $\beta$-carotene, aloin A and astaxanthin. The authors concluded that, compared to MAE and a common solvent extraction method, the vacuum MAE system was characterized by a better extraction [184]. In conclusion, the main advantages of MAE are improved extraction rates, reduced or eliminated use of solvents and reduced extraction time, resulting in decreased costs and environmental impact. Due to these strong benefits, MAE is considered as a good alternative to traditional extraction processes (such as solid-liquid extraction) for the extraction of plant metabolites. However, the efficiency of microwaves is very poor when targeted compounds are non-polar or volatile, therefore, as mentioned above, innovative approaches are needed for overcome these shortcomings.

PEF has advantages over other techniques that result in both a decrease in energetic and monetary expenditure, increasing efficiency 
Table 2

A few examples of optimization model used so far for bioactive compounds extraction from different plantsunder different extraction techniques.

\begin{tabular}{|c|c|c|c|c|c|}
\hline $\begin{array}{l}\text { S. } \\
\text { No. }\end{array}$ & Species & $\begin{array}{l}\text { Bioactive } \\
\text { compounds }\end{array}$ & $\begin{array}{l}\text { Extraction } \\
\text { technique }\end{array}$ & $\begin{array}{l}\text { Optimization } \\
\text { model }\end{array}$ & Reference \\
\hline 1 & $\begin{array}{l}\text { Coptis } \\
\text { chinensis }\end{array}$ & Alkaloids & UAE & $\mathrm{CCD}$ & [219] \\
\hline 2 & Ginseng & Saponins & MAE & $\mathrm{CCD}$ & {$[220]$} \\
\hline 3 & $\begin{array}{l}\text { Macleaya } \\
\text { cordata }\end{array}$ & $\begin{array}{l}\text { Protopine and } \\
\text { allocryptopine }\end{array}$ & MAE & $\mathrm{BBD}$ & [221] \\
\hline 4 & $\begin{array}{l}\text { Sparganii } \\
\text { Rhizoma }\end{array}$ & Flavonoids & UAE & $\mathrm{BBD}$ & {$[222]$} \\
\hline 5 & $\begin{array}{l}\text { Stepharia } \\
\text { sinica }\end{array}$ & Alkaloids & MAE & $\mathrm{BBD}$ & {$[223]$} \\
\hline 6 & Areca catechu & Polyphenols & UAE & $\mathrm{CCD}$ & {$[224]$} \\
\hline 7 & Cortex traxini & $\begin{array}{l}\text { Aesculin and } \\
\text { Aesculetin }\end{array}$ & UAE & $\mathrm{BBD}$ & {$[225]$} \\
\hline 8 & $\begin{array}{l}\text { Rheum } \\
\text { palmatum }\end{array}$ & Anthraquinones & UAE & $\mathrm{BBD}$ & {$[226]$} \\
\hline 9 & Apricot & beta-carotene & SFE & $\mathrm{CCD}$ & {$[227]$} \\
\hline 10 & $\begin{array}{l}\text { Eclipta } \\
\text { prostrasta }\end{array}$ & Saponins & UAE & $\mathrm{BBD}$ & {$[228]$} \\
\hline 11 & Puerariae Radix & Puerarin & UAE & $\mathrm{BBD}$ & [229] \\
\hline 12 & $\begin{array}{l}\text { Berberis } \\
\text { asiatica }\end{array}$ & Polyphenols & MAE & $\begin{array}{l}\mathrm{PBD} \text { and } \\
\mathrm{BBD}\end{array}$ & [230] \\
\hline 13 & $\begin{array}{l}\text { Berberis } \\
\text { jaeschkeana }\end{array}$ & Polyphenols & MAE & $\begin{array}{l}\text { PBD and } \\
\text { CCD }\end{array}$ & {$[231]$} \\
\hline 14 & $\begin{array}{l}\text { Cyperus } \\
\text { rotundus }\end{array}$ & Essential oil & SFE & $\mathrm{CCD}$ & [232] \\
\hline 15 & $\begin{array}{l}\text { Evodia } \\
\text { rutaecarpa }\end{array}$ & $\begin{array}{l}\text { Evodiamine and } \\
\text { rutaecarpine }\end{array}$ & SFE & $\mathrm{BBD}$ & {$[233]$} \\
\hline 16 & Apple & Polyphenols & PLE & $\mathrm{CCD}$ & {$[234]$} \\
\hline 17 & Potato & Alkaloids & PLE & $\mathrm{CCD}$ & {$[235]$} \\
\hline 18 & $\begin{array}{l}\text { Catharanthus } \\
\text { roseus }\end{array}$ & Alkaloids & EAE & $\mathrm{BBD}$ & [35] \\
\hline 19 & $\begin{array}{l}\text { Tricholoma } \\
\text { matsutake }\end{array}$ & Polysaccharides & EAE & $\mathrm{CCD}$ & [236] \\
\hline 20 & Corn silk & Polysaccharides & PEF & $\mathrm{BBD}$ & {$[237]$} \\
\hline 21 & $\begin{array}{l}\text { Potato } \\
\text { (Solanum } \\
\text { tuberosum) }\end{array}$ & Anthocyanins & PEF & $\mathrm{CCD}$ & [238] \\
\hline 22 & $\begin{array}{l}\text { Hippophae } \\
\text { thamnoides }\end{array}$ & Oil carotenoids & SFE & $\mathrm{CCD}$ & [239] \\
\hline 23 & $\begin{array}{l}\text { Xanthoceras } \\
\text { sorbifolia }\end{array}$ & Saponins & MAE & $\mathrm{CCD}$ & [240] \\
\hline
\end{tabular}

$\mathrm{MAE}=$ microwave assisted extraction, $\mathrm{UAE}=$ ultrasonic assisted extraction, $\mathrm{SFE}=$ supercritical fluid extraction, $\mathrm{PEF}=$ pulsed electric field, $\mathrm{PLE}=$ pressurized liquid extraction, $\mathrm{EAE}=$ enzyme assisted extraction, $\mathrm{CCD}=$ central composite design, $\mathrm{BBD}=\mathrm{Box}-\mathrm{Behnken}$ design, $\mathrm{PBD}=$ Plackett-Burman design.

and improving environmental impact, thus making PEF an interesting potential treatment in extracting bioactive compounds from a variety of different matrices [185]. However, with our current degree of understanding PEF presents two main problems for industrial applications. First of all, the non-uniform nature of the ideal distribution of the electric pulses, and secondly the pool of suitable solvents is very limited. Furthermore, an additional cooling system is necessary to control the potential heat generated by high-intensity PEF treatments when extracting thermolabile compounds [186].

EAE is a very useful method for obtaining extracts for use in the food industry. However, it has severe limitations due to the different behavior of enzymes at different process conditions and the limit in commercial availability of certain enzyme types; indeed, often the enzymes on the market are characterized by low selectivity and low variability. These are major obstacles to the scale-up of the EAE process on the industrial level [19]. Another emerging technique for extraction that is considered as a powerful alternative to the conventional methods is the PLE [82]. PLE has many advantages such as, that it can use water, hydrophilic or even organic solvents for extraction and it can operate at a pressure between 100 and $600 \mathrm{MPa}$ at a temperature ranging from 20 to $60^{\circ} \mathrm{C}$, such conditions are suitable for extraction of thermo-labile and unstable compounds [82]. PLE has easy automation, shorter analysis time, higher repeatability, smaller amount of solvents, lower risk of using toxic solvents and keeping the samples in a light- and oxygen-free environment [43].

Many other extraction techniques were developed to improve extraction efficiency from plants, among which SFE has the advantage of not requiring an alternative energy source c. f. microwave and ultrasound assisted extraction. Moreover, SFE is a modern and eco-friendly technique for extraction of bioactive compounds from plants. Subcritical water has also the advantage that its dielectric constant is variable under variable conditions. However, there are two limitations on using SFE, the first is the need of high temperature to reach the subcritical condition and this might cause destruction the bioactive natural compounds, and the second is that the low efficiency of subcritical water in extracting the different classes of compounds [187]. For these reasons, ethanol may be used instead of water especially because the supercritical or subcritical temperature of ethanol is much lower than water and also it is a somewhat safe solvent for human [188]. The scaling of extraction methods to industrial scale is not an easy task as there are some disadvantages in term of insufficient recovery, degradation due to excessive heating and extraction time, which ultimately results in high-energy consumption [189].

\subsection{Special emphasis on oil extraction from botanicals}

Conventional methods, using organic solvent for extraction is the most common method for preparing natural oils as the pine kernel oil [190] others uses mechanical processing [191]. However, the high cost together with the effect on environmental pollution, due to the organic solvents used threatening human's life, limited the use of conventional methods.

Among the different solvents used for oil extraction, hexane-extraction proved to be the best for nutraceutical and pharmaceutical value. Being a petrol-sourced compound, it has a negative impact on health, classified under C.M.R. (carcinogenic, mutagenic and reprotoxic) solvent and also found to be explosive. Moreover, hexane has been classified as C.M.R. (carcinogenic, mutagenic and reprotoxic) solvent. Additionally, applying high temperatures during hexane-extraction could affect the quality of extracted oil [192,193]. The hazards of the organic solvent residues limited the use of the conventional extraction methods and enforced the need for the development of environmentally friendly, economical extraction methods to replace conventional techniques. As such, aqueous enzymatic processing (AEP) has been recently applied for extracting the edible oil from various seeds, this method is characterized by being safer for health and cleaner for the environment so it can be alternative for traditional methods for oil extraction [194]. During the last decade's recommendation for the use of mixture of enzymes for extraction and improving quality of oil was proposed [195]. Results evidenced that enzymatic hydrolysis causes the cell wall lysis under mild temperatures, leading to higher permeability facilitating the oil extraction and minimizing solvent hazards. As per the six principles defined by Chemat et al. [2], this method provides an alternative method for green extraction. AEP depends on enhancing the oil permeability through the degradation of the cell walls that is caused by the enzymes; however the permeability of the cell membrane can be further increased by application of microwave [194], ultrasound [196] or heating [197] during AEP. Joining these strategies together shows more power in debasement of the cell wall destruction and increases the mass transfer between the enzyme solution and the plant lattice facilitates the oil release, enhancing oil yield, and shortening handling time [198,199].

Chen et al. [200] developed a novel extraction design, which included a homogenate-circulating ultrasound in combination with aqueous enzymatic extraction (H-CUAEE), for the extraction of oil 
Table 3

Comparative study of different extraction techniques under different parameters.

\begin{tabular}{|c|c|c|c|c|c|c|c|c|}
\hline Parameters & Maceration & $\begin{array}{l}\text { Soxhlet } \\
\text { extraction }\end{array}$ & SFE & MAE & UAE & EAE & PLE & PEF \\
\hline $\begin{array}{r}\text { Solvent used } \\
\text { (Preferably) }\end{array}$ & $\begin{array}{l}\text { Ethanol, } \\
\text { methanol, } \\
\text { water }\end{array}$ & $\begin{array}{l}\text { Non-polar } \\
\text { solvents } \\
\text { (hexane, ether, } \\
\text { petroleum ether) }\end{array}$ & $\begin{array}{l}\text { Carbon dioxide } \\
\text { (methanol or } \\
\text { ethanol can be } \\
\text { used as co- } \\
\text { solvents) }\end{array}$ & $\begin{array}{l}\text { Any solvent that absorb } \\
\text { microwave/solvent free }\end{array}$ & $\begin{array}{l}\text { Ethanol, } \\
\text { methanol and } \\
\text { water }\end{array}$ & $\begin{array}{l}\text { Enzymes (cellulase, } \\
\text { pectinase, } \\
\text { hemicellulase) }\end{array}$ & $\begin{array}{l}\text { Ethanol, } \\
\text { methanol, } \\
\text { water, other } \\
\text { organic } \\
\text { solvents }\end{array}$ & $\begin{array}{l}\text { Organic } \\
\text { solvents } \\
\text { and water }\end{array}$ \\
\hline Temperature & $\begin{array}{l}\text { Room } \\
\text { temperature }\end{array}$ & Heat applied & Above $31^{\circ} \mathrm{C}$ & Heat applied & $\begin{array}{l}\text { If required, } \\
\text { heat applied }\end{array}$ & Applied (water bath) & Applied & Not applied \\
\hline Duration & $2-5$ days & $2-18 \mathrm{~h}$ & Up to $1 \mathrm{~h}$ & $1-40 \min$ & $1 \mathrm{~h}(\max )$. & $1-12 \mathrm{~h}$ & $1-2 \mathrm{~h}$ & Few seconds \\
\hline $\begin{array}{l}\text { Volume of } \\
\text { solvent }\end{array}$ & $100 \mathrm{ml}$ to $3 \mathrm{~L}$ & Up to $1 \mathrm{~L}$ & - & Up to few hundred $\mathrm{ml}$ & $\mathrm{Up}$ to $250 \mathrm{ml}$ & Up to few liters & $\begin{array}{l}\text { Up to few } \\
\text { hundred } \mathrm{ml}\end{array}$ & $\begin{array}{l}\text { Up to few } \\
\text { hundred } \mathrm{ml}\end{array}$ \\
\hline Pressure & Not applied & Not applied & Applied & Not applied & Not applied & Not applied & Applied & Not applied \\
\hline $\begin{array}{l}\text { Plant part } \\
\text { preferred }\end{array}$ & Any plant part & $\begin{array}{l}\text { Seed and fruits in } \\
\text { particular }\end{array}$ & Any plant part & Any plant part & Any plant part & Any plant part & Any plant part & $\begin{array}{l}\text { Any plant } \\
\text { part }\end{array}$ \\
\hline $\begin{array}{l}\text { Large scale } \\
\text { application }\end{array}$ & Available & Available & Available & Possible & $\begin{array}{l}\text { Available but } \\
\text { limited } \\
\text { because of } \\
\text { the higher } \\
\text { cost and } \\
\text { nonlinearity } \\
\text { of process }\end{array}$ & Not available & Possible & Possible \\
\hline $\begin{array}{l}\text { Green } \\
\text { Extraction }\end{array}$ & Not possible & Not possible & Possible & Possible & Possible & Possible & Possible & Possible \\
\hline
\end{tabular}

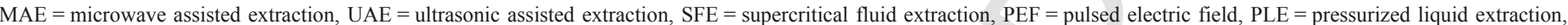
$\mathrm{EAE}=$ enzyme assisted extraction.

from the kernels of Pinus pumila. The effect of enzyme type, single enzyme or mixture of three enzymes, cellulase, hemicellulase and pectinase, as well as the enzyme concentration was evaluated. Latif and Anwar [201] reported that the type of the chosen enzyme and its concentration is crucial for oil extraction, as various enzymes function via different hydrolytic mechanisms. For instance, cellulase, hemicellulase and pectinase can damage cell walls besides destroying cell structural integrity. Furthermore, several proteins which are present in cells are capable of surrounding the oil molecules, thus preventing the release of oil molecules and protease may be used which have an impact on the breakdown of protein networks of oleosin-based membranes which envelopes the lipid bodies resulting in better oil release from lipid bodies.

Another alternative method to the traditional solvent extraction for oil is the MAE. MAE was used for extraction of many oils such as olive oil from dry olive pomace; the authors in this study employed a modified domestic microwave oven for extraction of the oil [202]. MAE provided an efficient method for extraction of oils in short time through destroying the cell walls of the plant tissues by its fast heating mechanism $[203,204]$, and has proved many benefits such as the higher yields of the extracted compounds [204,205], lower oxidation [206] and lesser consumption of solvents [207]. Driven by a need to be environmentally friendly, solvent-free MAE techniques have been developed. It uses internal water of the plant cells to heat up by microwave and leads to rupture cell wall, causing a release of both essential oils and internal water to the plant matrix, without adding any water or solvent. To separate the fatty phase, which contains essential oils and non-polar molecules, from the aqueous phase, which contains the polar compounds, Chemat et al. [208] developed and patented a Microwave Hydrodiffusion System in 2008. This system is composed of a microwave connected to a cooling system, which separates essential oils without the need for distillation (a very expensive step in terms of money and energy) (EU patent number: EP1995749A1). In 2012, Lee et al. [209] patented a similar apparatus, which differs from the Chemat patent by the addition of an inert gas flow (helium or nitrogen), which allows for better transposition of volatile molecules out from the oven and into the cooling system (US patent number: US8282789B2).
Yanik [210] used MAE in the preparation of olive oil from its wet pomace and compared its yield and characteristics with the oil prepared by the conventional extraction method (CE). On comparing the different parameters, the color of MAE oil was almost yellow, while it comes in dark green color under CE condition, which may be due to the effect of the high temperature and longer extraction time during CE condition as compared to MAE. Also, the quality of oil in terms of free fatty acid under MAE was found significantly higher as compared to CE. Lower peroxidase value of oil under MAE was also reported [210].

The advanced extraction method as compared to conventional produce higher yield and quality of oil (Table 4). For instance, the olive pomace oil extracted by UAE had higher quality and yield than that by SE. This could be attributed to the high temperature applied in SE affecting bioactive compounds. In addition, UAE method provides lower operating temperature and shorter extraction time leading to saving energy and achieving olive pomace oils both with high activity and rich in bioactive compounds. Also, pretreatment effect of microwave was found to increase the oil extraction yield from rapeseed, hazelnuts, flaxseed and purslane seed [203,211-213]. SFE is another alternative and effective method for oil extraction. This method avoids degradation of thermolabile compounds and hydrosolubilization or hydrolysis of sensible compounds. For instance, remarkable differences were detected among the essential oil composition and the corresponding SFE extracts. The composition and percentage of compounds such as $\alpha$-pinene and 1,8- cineole were comparably different and higher under SFE [214].

PLE technique has also been used to extract aromatic compounds and to isolate essential oils from plant materials [215]. This technique was reported as fast, clean and highly efficient for extraction of essential oils. Eikani and co-workers reported the essential oil extraction yield from Cuminum cyminum at $150^{\circ} \mathrm{C}$ under PLE green extraction, which was comparable to SE and hydrodistillation [216]. Similar results were obtained comparing PLE with conventional methods for the extraction of borneol [217] and pulegone [218] from vegetal sources. 
Table 4

Comparative study of oil extraction using different extraction techniques.

\begin{tabular}{|c|c|c|c|c|}
\hline Genus & Part of plant & $\begin{array}{l}\text { Extraction } \\
\text { Method }\end{array}$ & $\begin{array}{l}\text { Oil } \\
\text { Yield } \\
(\%)\end{array}$ & References \\
\hline \multirow[t]{4}{*}{ Punica granatum } & $\begin{array}{l}\text { Microwave } \\
\text { treated seeds }\end{array}$ & $\begin{array}{l}\text { Supercritical } \\
\text { carbon dioxide } \\
\left(\mathrm{Sc}-\mathrm{CO}_{2}\right)\end{array}$ & 25.5 & \multirow[t]{4}{*}[241]{} \\
\hline & $\begin{array}{l}\text { Microwave } \\
\text { treated seeds }\end{array}$ & $\begin{array}{l}n \text {-hexane in } \\
\text { Soxhlet } \\
\text { apparatus }\end{array}$ & 34.0 & \\
\hline & $\begin{array}{l}\text { Untreated } \\
\text { seeds }\end{array}$ & $\begin{array}{l}\text { Supercritical } \\
\text { carbon dioxide } \\
\left(\mathrm{Sc}-\mathrm{CO}_{2}\right)\end{array}$ & 21.6 & \\
\hline & $\begin{array}{l}\text { Untreated } \\
\text { seeds }\end{array}$ & $\begin{array}{l}n \text {-hexane in } \\
\text { Soxhlet } \\
\text { apparatus }\end{array}$ & 27.7 & \\
\hline \multirow[t]{2}{*}{ Polygonum minus } & \multirow[t]{2}{*}{ Whole plant } & $\begin{array}{l}\text { Inonic liquid } \\
\text { microwave } \\
\text { assisted } \\
\text { extraction } \\
\text { (ILMAE) with } \\
\text { Clevenger } \\
\text { apparatus }\end{array}$ & 9.6 & \multirow[t]{2}{*}[242]{} \\
\hline & & $\begin{array}{l}\text { Inonic liquid } \\
\text { Ultrasound } \\
\text { assisted } \\
\text { extraction } \\
\text { (ILUAE) with } \\
\text { Clevenger } \\
\text { apparatus }\end{array}$ & 9.5 & \\
\hline Cymbopogon citrates & Whole plant & $\begin{array}{l}\text { Water-distilled } \\
\text { (WD), } \\
\text { microwave- } \\
\text { distilled (MD), } \\
\text { acid-distilled } \\
\text { (AD), base- } \\
\text { distilled (BD) }\end{array}$ & $\begin{array}{c}0.73 \\
0.64 \\
0.70 \\
0.45\end{array}$ & [243] \\
\hline \multirow[t]{4}{*}{ Pistacia vera } & \multirow[t]{4}{*}{ Leaves } & $\begin{array}{l}\text { Microwave } \\
\text { assisted } \\
\text { extraction } \\
\text { (MAE) }\end{array}$ & 48.11 & \multirow[t]{8}{*}[244]{} \\
\hline & & $\begin{array}{l}\text { Ultrasound } \\
\text { assisted } \\
\text { extraction } \\
\text { (UAE) }\end{array}$ & 39.39 & \\
\hline & & $\begin{array}{l}\text { Supercritical } \\
\text { fluid extraction } \\
\text { (SFE) }\end{array}$ & 22.3 & \\
\hline & & $\begin{array}{l}\text { Conventional } \\
\text { Soxhlet } \\
\text { extraction (SE) }\end{array}$ & 31.99 & \\
\hline \multirow[t]{4}{*}{ Lophira lanceolata } & \multirow[t]{4}{*}{ Seeds } & $\begin{array}{l}\text { Ancestral } \\
\text { techniques } \\
\text { using roasted } \\
\text { seeds }\end{array}$ & 32.44 & \\
\hline & & $\begin{array}{l}\text { Oil obtained } \\
\text { from roasted } \\
\text { seeds with } \\
\text { enzymes } \\
\text { mixtures }\end{array}$ & 38.53 & \\
\hline & & $\begin{array}{l}\text { Soxhlet } \\
\text { apparatus in } \\
\text { hexane from } \\
\text { fresh seeds } \\
\text { (non-roasted } \\
\text { seed) }\end{array}$ & 42.97 & \\
\hline & & $\begin{array}{l}\text { Oil extracted } \\
\text { with hexane } \\
\text { from roasted } \\
\text { seeds }\end{array}$ & 42.32 & \\
\hline
\end{tabular}

Table 4 (Continued)

\begin{tabular}{|c|c|c|c|c|}
\hline Genus & Part of plant & $\begin{array}{l}\text { Extraction } \\
\text { Method }\end{array}$ & $\begin{array}{l}\text { Oil } \\
\text { Yield } \\
(\%)\end{array}$ & References \\
\hline Portulaca oleracea & Seeds & $\begin{array}{l}\text { Ultrasound } \\
\text { assisted } \\
\text { extraction } \\
\text { (UAE) } \\
\text { Solvent } \\
\text { extraction } \\
\text { Cold press } \\
\text { MW-cold press }\end{array}$ & $\begin{array}{r}4.16 \text { to } \\
10.88 \\
72.31 \\
\\
59.37 \\
65.88 \\
\end{array}$ & {$[132,246]$} \\
\hline
\end{tabular}

\subsection{Trends of extraction techniques: compounds, plant parts and patents}

The trends of bioactive compounds extracted under different extraction methods were determined using Scopus database (https:// www.scopus.com/) search as per the defined parameters (Table 5). Among all the potential bioactive compound classes included in this review, flavonoids are the most frequently extracted. Flavonoids are a larger group of bioactive compounds, divided into several subclasses such as flavonols, flavones, isoflavonoids, flavanones, flavanonols, flavans and anthocyanidines, which have wider applications and thus are extracted most often. Oil extraction showed the highest number of papers, due to its higher commerce value and wide numbers of compounds (Fig. 4). It is interesting to see that Soxhlet extraction technique showed higher or similar number of papers for extraction of different compounds. This is due to the fact that Soxhlet is a widely used old method $c$. $f$. advanced one. Among advanced extraction techniques, most of the compounds are better extracted with SFE. It is the most advanced extract preparation technique, which results in higher quality of the extract with minimum environmental lose. For instance, oils, alkaloids, carotenoids and anthocyanins are mostly extracted through SFE technique (Fig. 4). These compounds are in higher demand, and also some of them are sensitive to process factors, thus need to be extracted in high quality with minimum loss, possibly with SFE. Other than SFE, which is of high processing cost, MAE is used extensively for extraction of these compounds, due to its flexibility, and it's fast, easy and low cost of operations. It has also

Table 5

Parameters used during the search for articles in Scopus (www.scopus.com).

\begin{tabular}{ll}
\hline Search parameters & Operational Settings \\
\hline Search term text & i) "Soxhlet", "Supercritical fluid extraction", and \\
& So on for individual parameters (Table 6 for \\
& Patents) \\
& ii) "Soxhlet" AND "Anthocyanins", \\
"Supercritical fluid extraction" AND & "Anthocyanins", and so on for individual \\
& parameters (Figure 6 for chemical class and \\
& extraction method) \\
& iii) "Soxhlet" AND "Roots", "Supercritical fluid \\
& extraction" AND "Roots", and so on for \\
& individual parameters (Figure 7 for extraction \\
& method and plant parts) \\
& iv) "Anthocyanins" AND "Roots", \\
"Anthocyanins" AND "Rhizomes", and so on \\
for individual parameters (Table 7 for chemical \\
class and plant part) \\
Article title, Abstract, Keywords \\
All years to present \\
All \\
Sate range & Patents for (i) and Articles for others \\
Dobject Areas & AND \\
Operator used between two & \\
search items & \\
\hline
\end{tabular}


the advantage to be useful for both polar and non-polar compounds. Among all compounds, anthocyanins, polyphenols, flavonoids and saponins are largely extracted by using MAE technique (Fig. 4). Despite being an older technique, the UAE is not widely used for the extraction of compounds $c$. $f$. MAE and SFE techniques. The possible reason could be the failure of instrumentation set-up when upscale to pilot or industrial use. Furthermore, the UAE process is non-linear and has degradation issues related to compounds prone to free radical reaction, thus losing its acceptability in some cases. Other extraction techniques such as EAE, PLE and PEF are new techniques, and have lower acceptability. Among these, PLE is being used extensively in the extraction of compounds due to its fast and environmentally friendly process and having the flexibility to optimize process factors w.r.t. EAE and PEF. However, EAE depends on the enzyme type, concentration, kinetics and conditions, thus limiting its use. Similarly, a limited amount of solvents is currently being used under PEF, thus leading to lower acceptability. This has been also noted when analyzing data on the number of patents registered so far on using these techniques for extraction of compounds (Table 6). Interestingly, PLE technique registered a much higher numbers of patents $c$. $f$. UAE, EAE and PEF. SFE secured higher followed by MAE, while Soxhlet was found to be the most patented technique for extraction of compounds.

Table 6

Patents registered so far for the extraction of compounds using different extraction techniques.

\begin{tabular}{lll}
\hline Extraction method & Short form & No. of patents \\
\hline Soxhlet & Soxhlet & 33,753 \\
Supercritical fluid extraction & SFE & 7550 \\
Microwave assisted extraction & MAE & 637 \\
Ultrasonic assisted extraction & UAE & 66 \\
Enzyme assisted extraction & EAE & 28 \\
Pressurized liquid extraction & PLE & 158 \\
Pulsed electric field extraction & PEF & 8 \\
\hline
\end{tabular}

Source: Scopus (accessed on August 4, 2017).
Regarding the type of plant part being used for extraction of compounds, Soxhlet extraction method comes as highly used method for extraction of compounds including all plant parts (leaves, roots, rhizomes, bark, fruits and flowers), which may be due to its earlier discovery than advanced techniques (Fig. 5). Among the advanced extraction techniques, SFE secured highest position in terms of publications dealing with the extraction of compounds from different plant parts and leaves showed higher number of papers (Fig. 5). In total, extraction of compounds from leaves showed the highest number followed by fruits, root, bark, flowers and rhizome (Fig. 5). The accumulation of different compounds varies among different plant parts, thus influencing extraction trends. As such, fruits are better known as a source for anthocyanins, polyphenols, polysaccharide and carotenoids extraction, while leaves contain more alkaloids, flavonoids, oils and saponins (Table 7).

\section{Conclusion and future prospective}

Trends of extraction techniques have been changing, as more advanced techniques that utilize green extraction concept have been emerging. The advantage of such techniques has been immense in producing good quality yield, lesser solvent and energy consumption and shorter extraction time. However, advanced extraction methods have limitations in scale-up to pilot or industrial purposes. The value changes and the laboratory-based experimentation conditions are mostly not optimized for industrial use. Thus, development of economically feasible industrial extraction methods and instruments for mass extraction is the need of the hour.

The development of cost-effective and eco-friendly extraction methodologies for greater recovery of bioactive compounds at lesser process time from natural sources is the main objective of modern analytical research. However, no single extraction technique was found effective for extraction of all compounds. Thus the most suitable extraction technique depends on plant matrices and compound type, and defined selection criteria should be followed. In addition, combining extraction methods often has advantages to overcome the limitations of an individual method. On the other hand, strategies for high effi-

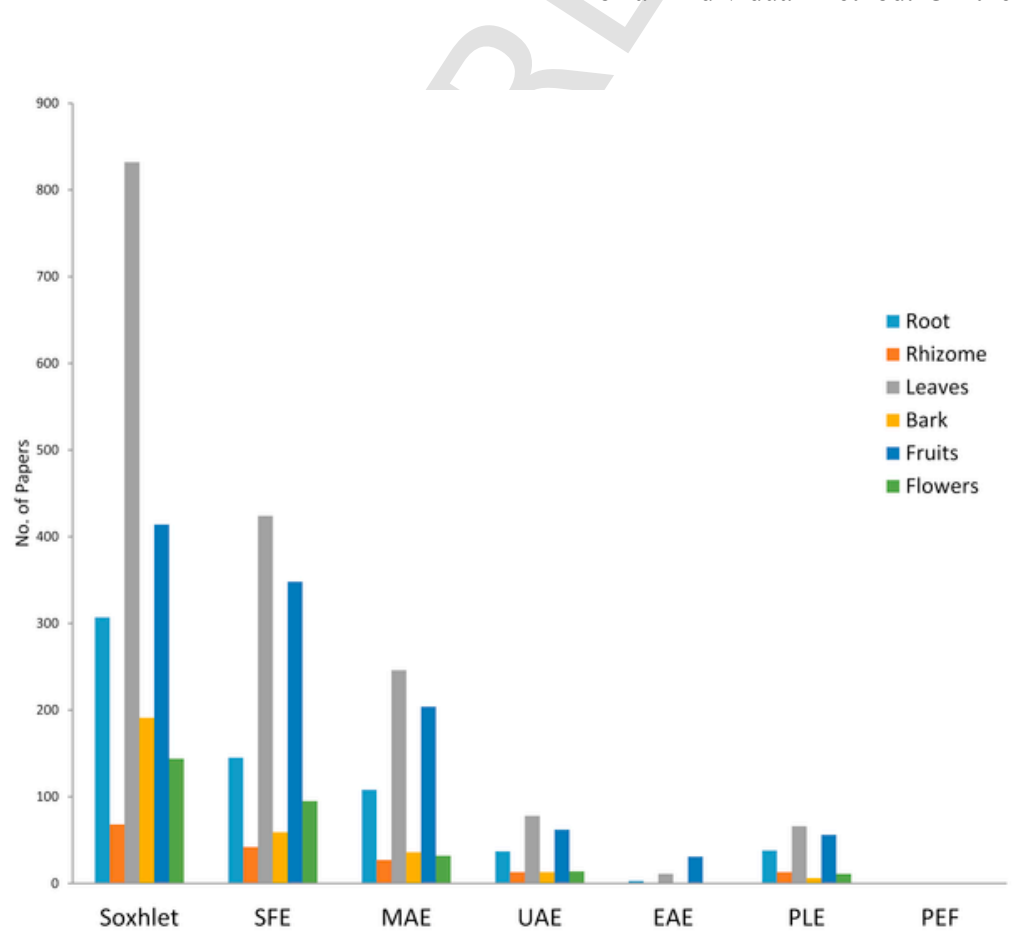

Fig. 5. Trends of extraction using different plant parts under different extraction processes. 
Table 7

List of papers dealing with chemical compounds extracted using different plant parts.

\begin{tabular}{lllllll}
\hline Chemical classes & Roots & Rhizomes & Leaves & Bark & Fruits & Flowers \\
\hline Anthocyanins & 1108 & 46 & 3041 & 151 & 7284 & 2276 \\
Polyphenols & 1822 & 278 & 5382 & 815 & 7780 & 748 \\
Polysaccharides & 2902 & 237 & 2650 & 333 & 3043 & 449 \\
Alkaloids & 6428 & 744 & 8482 & 2932 & 2174 & 1183 \\
Flavonoids & 5693 & 805 & 14,904 & 2556 & 10,483 & 3739 \\
Oils & 9472 & 1378 & 18,519 & 2069 & 15,714 & 4771 \\
Carotenoids & 1971 & 56 & 5077 & 89 & 6257 & 945 \\
Saponins & 3850 & 881 & 4546 & 1261 & 1348 & 649 \\
\hline
\end{tabular}

Source: Scopus (accessed on August 4, 2017).

ciency extraction and the need for reuse/recycling of the solvents used, is always associated with high operating costs and energy consumption. Accordingly, the search for alternative green extraction methods is of great importance for effective and economical yield of compounds with lesser negative environmental impacts. Convenient separation of chemical constituents requires the use of organic solvents, but serious concerns are always raised on using low boiling point and hazardous solvents, which may be related to storage, toxicity, flammability and worker exposure. As a consequence, the search for innovative and safe extraction processes, with the aim of maximizing extraction efficiency and safety is highly relevant.

In this review, we have summarized the recent development on the advanced techniques for extraction of botanicals. With the increasing demand of plant based natural products for drug discovery, development of functional foods or nutraceuticals and cosmetics, newer methods of extractions and their optimizations might be developed in future. These techniques should focus on their application on extraction of various chemical classes of compounds in economical and environment friendly ways and wider industrial application to meet future demands.

\section{Acknowledgement}

A.G.A. acknowledges the support of the Polish KNOW (Leading National Research Center) Scientific Consortium "Healthy Animal-Safe Food," decision of Ministry of Science and Higher Education No. 05-1/KNOW2/2015.

\section{Appendix A. Supplementary data}

Supplementary data related to this article can be found at https:// doi.org/10.1016/j.trac.2017.12.018.

\section{References}

[1] A. Khoddami, M. Wilkes, T. Roberts, Techniques for analysis of plant phenolic compounds, Molecules 18 (2013) 2328-2375.

[2] F. Chemat, M.A. Vian, G. Cravotto, Green extraction of natural products: concept and principles, Int. J. Mol. Sci. 13 (2012) 8615-8627.

[3] K. Ganzler, I. Szinai, A. Salgo, Effective sample preparation method for extracting biologically active compounds from different matrices by a microwave technique, J. Chromatogr. A 520 (1990) 257-262.

[4] P.C. Veggi, J. Martinez, M.A.A. Meireles, Fundamentals of Microwave Extraction. In Microwave-assisted Extraction for Bioactive Compounds, Springer US, 201215-52.

[5] W. Specht, Z. Lebensm.-Untersuch. ul-Forsch. 94 (1952) 157.

[6] W. Specht, W.E. Schulteis, Beer Brewing Process, US2,816,031. Germany, 195710.

[7] M. Vinatoru, T.J. Mason, I. Calinescu, Ultrasonically assisted extraction (UAE) and microwave assisted extraction (MAE) of functional compounds from plant materials, Trends Analyt. Chem. 97 (2017) 159-178.

[8] B. Miljevic, F. Hedayat, S. Stevanovic, K.E. Fairfull-Smith, S.E. Bottle, Z.D. Ristovski, To sonicate or not to sonicate PM filters: reactive oxygen species generation upon ultrasonic irradiation, Aerosol Sci. Tech 48 (2014) 1276-1284
[9] M. Biesaga, K. Pyrzyńska, Stability of bioactive polyphenols from honey during different extraction methods, Food Chem. 136 (2013) 46-54.

[10] L. Qiao, Y. Sun, R. Chen, Y. Fu, W. Zhang, X. Li, J. Chen, Y. Shen, X. Ye, Sonochemical effects on 14 flavonoids common in citrus: relation to stability, PloS one 9 (2014) e87766.

[11] F. Chemat, N. Rombaut, A.G. Sicaire, A. Meullemiestre, A.S. Fabiano-Tixier M. Abert-Vian, Ultrasound assisted extraction of food and natural products.

Mechanisms, techniques, combinations, protocols and applications. A review, Ultrason. Sonochem. 34 (2017) 540-560.

[12] H. Jaeger, M. Schulz, P. Lu, D. Knorr, Adjustment of milling, mash electroporation and pressing for the development of a PEF assisted juice production in industrial scale, Innov. Food Sci.Emerg. Tech 14 (2012) 46-60.

[13] A.J.A. Sale, W.A. Hamilton, Effects of high electric fields on microorganisms: I. Killing of bacteria and yeasts, Biochim. Biophys. Acta Gen. Subj. 148 (3) (1967) 781-788.

[14] S. Mahnič-Kalamiza, E. Vorobiev, D. Miklavčič, Electroporation in food processing and biorefinery, J. Membr. Biol. 247 (12) (2014) 1279-1304.

[15] F. Chemat, A.S. Fabiano-Tixier, M.A. Vian, T. Allaf, E. Vorobiev, Solvent-free extraction of food and natural products, Trends Analyt. Chem. 71 (2015) 157-168.

[16] M. Ngadi, V. Raghavan, T. Gachovska, The Royal Institution for the Advancement of Learning/Mcgill University, Pulsed electric field enhanced method of extraction. U.S. Patent 8,147,879 (2012).

[17] T.K. Gachovska, M. Ngadi, M. Chetti, G.V. Raghavan, Enhancement of lycopene extraction from tomatoes using pulsed electric field, In: Pulsed Power Conference (PPC), 2013 19th IEEE, 2013, pp. 1-5.

[18] P. Munish, S. Deepika, J.B. Colin, Enzyme-assisted extraction of bioactives from plants, Trends Biotechnol. 30 (2012) 37-44 http://www.sciencedirect. com/science/journal/01677799.

[19] A. Baiano, Recovery of biomolecules from food wastes - a review, Molecules 19 (2014) 14821-14842, https://doi.org/10.3390/molecules 190914821.

[20] K.Y. Khaw, M.O. Parat, P.N. Shaw, J.R. Falconer, Solvent supercritical fluid technologies to extract bioactive compounds from natural sources: a review, Molecules 22 (2017), pii: E1186.

[21] J.H. Doughari, Phytochemicals: extraction methods, basic structures and mode of action as potential chemotherapeutic agents, In: Phytochemicals-a Global Perspective of Their Role in Nutrition and Health, INTECH Open Access Publisher, 2012.

[22] P.S. Patil, R. Shettigar, An advancement of analytical techniques in herbal research, J. Adv. Sci. Res. 1 (2010) 8-14.

[23] A. Bertucco, G. Franceschin, Supercritical fluid extraction of medicinal and aromatic plants: fundamentals and applications, Extraction Technologies for Medicinal and Aromatic Plants (2008) 169-180, International Centre for Science and High Technology.

[24] O.J. Catchpole, J.B. Grey, K.A. Mitchell, J.S. Lan, Supercritical antisolvent fractionation of propolis tincture, J. Supercrit. Fluids 29 (2004) 97-106.

[25] O.J. Catchpole, S.J. Tallon, W.E. Eltringham, J.B. Grey, K.A. Fenton, E.M. Vagi, M.V. Vyssotski, A.N. MacKenzie, J. Ryan, Y. Zhu, The extraction and fractionation of specialty lipids using near critical fluids, J. Supercrit. Fluids 47 (2009) 591-597.

[26] Q.X. L, Judith R. Denery, K. Dragull, C.S. Tang, Pressurized fluid extraction of carotenoids from Haematococcus pluvialis and Dunaliella salina and kavalactones from Piper methysticum, Anal. Chim. Acta 501 (2004) 175-181.

[27] Y.-L.Y. Eng-Shi Ong, Soo-On Woo, Pressurized liquid extraction of berberine and aristolochic acids in medicinal plants, J. Chromatogr. A 904 (2000) 57-64.

[28] M.H. Björn Benthin, H. Danz, Pressurized liquid extraction of medicinal plants, J. Chromatogr. A 837 (1999) 211-219.

[29] D.Y. Zhang, X.H. Yao, M.H. Duan, M. Luo, W. Wang, Y.J. Fu, Y.G. Zu, T. Efferth, An effective negative pressure cavitation-microwave assisted extraction for determination of phenolic compounds in P. calliantha H. Andr, Analyst 138 (2013) 4631-4641.

[30] W. Liu, Y. Fu, Y. Zu, Y. Kong, L. Zhang, B. Zu, T. Efferth, Negative-pressure cavitation extraction for the determination of flavonoids in pigeon pea leaves by liquid chromatography-tandem mass spectrometry, J. Chromatogr. A 1216 (2009) 3841-3850

[31] F. Mu, L. Yang, W. Wang, M. Luo, Y. Fu, X. Guo, Y. Zu, Negative-pressure cavitation extraction of four main vinca alkaloids from Catharanthus roseus leaves, Molecules 17 (2012) 8742-8752.

[32] D.Y. Zhang, Y.G. Zu, Y.J. Fu, M. Luo, W. Wang, C.B. Gu, C.J. Zhao, J. Jiao, T. Efferth, Enzyme pretreatment and negative pressure cavitation extraction of genistein and apigenin from the roots of pigeon pea [Cajanus cajan (L.) Millsp.] and the evaluation of antioxidant activity, Ind. Crop. Prod. 37 (2012) 311-320.

[33] Y. Kong, Z.F. Wei, Y.J. Fu, C.B. Gu, C.J. Zhao, X.H. Yao, T. Efferth, Negative-pressure cavitation extraction of cajaninstilbene acid and pinostrobin from pigeon pea [Cajanus cajan (L.)Millsp.] leaves and valuation of antioxidant activity, Food Chem. 128 (2011) 596-605. 
[34] J. Jiao, F.Y. Wei, Q.Y. Gai, W. Wang, M. Luo, Y.J. Fu, W. Ma, A pilot-scale homogenization-assisted negative pressure cavitation extraction of Astragalus polysaccharides, Int. J. Biol. Macromol. 67 (2014) 189-194.

[35] M. Luo, L.-Q. Yang, X.-H. Yao, F.-S. Mu, D.-Y. Zhang, Z.-Y. Song, Q. Qiao, Y.-J. Fu, Y.-G. Zu, Optimization of enzyme-assisted negative pressure cavitation extraction of five main indole alkaloids from Catharanthus roseus leaves and its pilot-scale application, Separ. Purif. Technol. 125 (2014) 66-73.

[36] C.M. Galanakis, Recovery of high added-value components from food wastes: conventional, emerging technologies and commercialized applications, Trends Food Sci. Technol. 26 (2012) 68-87.

[37] M.A. Al-Mansoub, M.Z. Asmawi, V. Murugaiyah, Effect of extraction solvents and plant parts used on the antihyperlipidemic and antioxidant effects of Garcinia atroviridis : a comparative study, J. Sci. Food Agric. 94 (2014) $1552-1558$.

[38] L.S.G.T. Alex, S.N. Trindade, A.F. Dantas, D.C. Lima, S.L.C. Ferreira, Multivariate optimization of ultrasound-assisted extraction for determination of $\mathrm{Cu}$, $\mathrm{Fe}, \mathrm{Ni}$ and $\mathrm{Zn}$ in vegetable oils by high-resolution continuum source atomic absorption spectrometry, Food Chem. 185 (2015) 145-150.

[39] N.N. Azwanida, Aromatic plants a review on the extraction methods use in medicinal plants, principle, strength and limitation, Med. Aromatic Plants 4 (2015) 2167-2412.

[40] C.H. Chan, R. Yusoff, G.C. Ngoh, F.W.L. Kung, Microwave-assisted extractions of active ingredients from plants, J. Chromatogr. A 1218 (2011) 6213-6225.

[41] M. Herrero, A. Cifuentes, E. Iban ez, Sub- and supercritical fluid extraction of functional ingredients from different natural sources: plants, food-by-products, algae and microalgae: a review,, Food Chem. 98 (2006) 136-148.

[42] Q. Lang, C.M. Wai, Supercritical fluid extraction in herbal and natural product studies - a practical review, Talanta 53 (2001) 771-782.

[43] A. Mustafa, C. Turner, Pressurized liquid extraction as a green approach in food and herbal plants extraction: a review, Anal. Chim. Acta 703 (2011) 8-18.

[44] F.J. Barba, Z. Zhu, M. Koubaa, A.S. Sant'Ana, V. Orlien, Green alternative methods for the extraction of antioxidant bioactive compounds from winery wastes and by-products: a review,, Trends Food Sci. Technol. 49 (2016) 96-109.

[45] K. Ameer, H.M. Shahbaz, J.H. Kwon, Green extraction methods for polyphenols from plant matrices and their byproducts: a review, Compr. Rev. Food Sci. Food Saf. 16 (2017) 295-315.

[46] W. Sookjitsumran, S. Devahastin, A.S. Mujumdar, N. Chiewchan, Comparative evaluation of microwave-assisted extraction and preheated solvent extraction of bioactive compounds from a plant material: a case study with cabbages, Int. J. Food Sci. Tech 51 (2016) 2440-2449.

[47] D.A.J. Starmans, H.H. Nijhuis, Extraction of secondary metabolites from plant material: a review, Trends Food Sci. Technol. 7 (1996) 191-196.

[48] L. Wang, C.L. Weller, Recent advances in extraction of nutraceuticals from plants, Trends Food Sci. Technol. 17 (2006) 300-312.

[49] H. Wijngaard, M.B. Hossain, D.K. Rai, N. Brunton, Techniques to extract bioactive compounds from food by-products of plant origin, Food Res. Int 46 (2012) 505-513.

[50] S. Roohinejad, M. Koubaa, F.J. Barba, R. Greiner, V. Orlien, N.I. Lebovka, Negative pressure cavitation extraction: a novel method for extraction of food bioactive compounds from plant materials, Trends Food Sci. Technol. 52 (2016) 98-108.

[51] J. Xi, Ultrahigh pressure extraction of bioactive compounds from plants-a review, Crit. Rev. Food Sci. Nutr. 57 (2015) 1097-1106.

[52] V. Mandal, R. Tandey, A critical analysis of publication trends from 2005-2015 in microwave assisted extraction of botanicals: how far we have come and the road ahead, Trends Anal. Chem. 82 (2016) 100-108.

[53] R. Bobinaitè, G. Pataro, N. Lamanauskas, S. Šatkauskas, P. Viškelis, G. Ferrari, Application of pulsed electric field in the production of juice and extraction of bioactive compounds from blueberry fruits and their by-products, J. Food Sci. Technol. 52 (2015) 5898-5905.

[54] E.Z. Aleksandra Zderic, Polyphenol extraction from fresh tea leaves by pulsed electric field: a study of mechanisms, Chem. Eng. Res. Des. 109 (2016) 586-592.

[55] J.R. Elisa Luengo, I. Álvarez, Improving the pressing extraction of polyphenols of orange peel by pulsed electric fields, Innovat. Food Sci. Emerg. Technol. 17 (2013) 79-84

[56] V. Bansal, A. Sharma, C. Ghanshyam, M.L. Singla, Optimization and characterization of pulsed electric field parameters for extraction of quercetin and ellagic acid in Emblica officinalis juice, J. Food Meas. Charact. 8 (2014) 225-233.

[57] A.D. Sousa, A.I.V. Maia, T.H.S. Rodrigues, K.M. Canuto, P.R.V. Ribeiro, R.D.C.A. Pereira, R.F. Vieira, E.S. de Brito, Ultrasound-assisted and pressurized liquid extraction of phenolic compounds from Phyllanthus amarus and its composition evaluation by UPLC-QTOF, Ind. Crop. Prod. 79 (2016) 91-103.

[58] F. Qiu, Z. Tong, J. Gao, M. Wang, M. Gong, Rapid and simultaneous quantification of seven bioactive components in Radix Astragali based on pressurized liquid extraction combined with HPLC-ESI-MS/MS analysis, Anal. Methods. 7 (2015) 3054-3062.

[59] S.C. Lao, S.P. Li, K.K. Kan, P. Li, J.B. Wan, Y.T. Wang, T.T. Dong, K.W. Tsim, Identification and quantification of 13 components in Angelica sinensis (Danggui) by gas chromatography-mass spectrometry coupled with pressurized liquid extraction, Anal. Chim. Acta 526 (2004) pp.131-137.

[60] G.L. Zabot, M.A.A. Meireles, On-line process for pressurized ethanol extraction of onion peels extract and particle formation using supercritical antisolvent, J. Supercrit. Fluids 110 (2016) 230-239.

[61] S. El Abdellaoui, E. Destandau, A. Toribio, C. Elfakir, M. Lafosse, I. Renimel, P. André, P. Cancellieri, L. Landemarre, Bioactive molecules in Kalanchoe pinnata leaves: extraction, purification, and identification, Anal. Bioanal. Chem. 398 (2010) 1329-1338.

[62] A. Sae-Yun, C. Ovatlarnporn, A. Itharat, R. Wiwattanapatapee, Extraction of rotenone from Derris elliptica and Derris malaccensis by pressurized liquid extraction compared with maceration, J. Chromatogr. A 1125 (2006) 172-176.

[63] A.N. Carla Da Porto, A. Natolino, Supercritical fluid extraction of polyphenols from grape seed (Vitis vinifera): study on process variables and kinetics, J. Supercrit. Fluids 130 (2017) 239-245

[64] E.E. Yilmaz, E.B. Özvural, H. Vural, Extraction and identification of proanthocyanidins from grape seed (Vitis vinifera) using supercritical carbon dioxide, J. Supercrit. Fluids 55 (2011) 924-928.

[65] R. Murga, R. Ruiz, C.J.L. Sagrario Beltrán, Extraction of natural complex phenols and tannins from grape seeds by using supercritical mixtures of carbon dioxide and alcohol, J. Agric. Food Chem. 48 (2000).

[66] Ž.K. Tünde Vatai, M. Škerget, Extraction of phenolic compounds from elder berry and different grape marc varieties using organic solvents and/or supercritical carbon dioxide, J. Food Eng. 90 (2009) 246-254.

[67] A.A. Jovanović, V.B. Đorđević, G.M. Zdunić, D.S. Pljevljakušić, K.P. Šavikin, D.M. Gođevac, B.M. Bugarski, Optimization of the extraction process of polyphenols from Thymus serpyllum L. herb using maceration, heat-and ultrasound-assisted techniques, Separ. Purif. Technol. 179 (2017) 369-380.

[68] N.T. Huynh, G. Smagghe, G.B. Gonzales, J. Van Camp, K. Raes, Enzyme-assisted extraction enhancing the phenolic release from cauliflower (Brassica oleracea L. var. botrytis) outer leaves, J. Agric. Food Chem. 62 (2014) $7468-7476$

[69] X.Y. Zhihao Zhou, H. Shao, X. Han, K. Wang, C. Gong, The extraction efficiency enhancement of polyphenols from Ulmus pumila L. barks by trienzyme-assisted extraction, Ind. Crop. Prod. 97 (2017) 401-408.

[70] B.P. Milica Ramić, S. Vidović, Z. Zeković, J. Vladić, A. Cvejin, Modeling and optimization of ultrasound-assisted extraction of polyphenolic compounds from Aronia melanocarpa by-products from filter-tea factory, Ultrason. Sonochem. 23 (2015) 360-368.

[71] S.S.H.R. Muhammad Mushtaq, B. Sultana, F. Anward, A. Adnan, Enzyme-assisted supercritical fluid extraction of phenolic antioxidants from pomegranate peel, J. Supercrit. Fluids 104 (2015) 122-131.

[72] P. Khuwijitjaru, J. Plernjit, B. Suaylam, S. Samuhaseneetoo, R. Pongsawatmanit, S. Adachi, Degradation kinetics of some phenolic compounds in subcritical water and radical scavenging activity of their degradation products, Can. J. Chem. Eng. 92 (2014) 810-815.

[73] T.S. Ballard, P. Mallikarjunan, K. Zhou, S. O'Keefe, Microwave-assisted extraction of phenolic antioxidant compounds from peanut skins, Food Chem. 120 (2010) 1185-1192.

[74] V. Dragović-Uzelac, V.I. Elez Garofulić, M. Jukić, M. Penić, M. Dent, The influence of microwave-assisted extraction on the isolation of sage (Salvia officinalis L.) polyphenols, Food Technol. Biotechnol. 50 (2012) 377-383.

[75] N. Hamzah, C.P. Leo, Microwave-assisted extraction of Trigona propolis: the effects of processing parameters, Int. J. Chem. Eng. 11 (2015) 861-870.

[76] I. Calinescu, V. Lavric, I. Asofiei, A.I. Gavrila, A. Trifan, D. Ighigeanu, D. Martin, C. Matei, Microwave assisted extraction of polyphenols using a coaxial antenna and a cooling system, Chem. Eng. Process 122 (2017) 373-379.

[77] H.F. Xiujuan Xie, D. Zhu, W. Zhang, W. Huai, K. Wang, X. Huang, L. Zhou, Microwave-assisted aqueous two-phase extraction coupled with high performance liquid chromatography for simultaneous extraction and determination of four flavonoids in Crotalaria sessiliflora L, Ind. Crop. Prod. 95 (2017) 632-642.

[78] H.F. Xunyou Tang, D. Zhu, W. Huai, W. Zhang, C. Fu, X. Xie, S. Quan, Simultaneous extraction and separation of flavonoids and alkaloids from Crotalaria sessiliflora L. by microwave-assisted cloud-point extraction, Separ. Purif. Technol. 175 (2017) 266-273.

[79] G. Zgórka, Pressurized liquid extraction versus other extraction techniques in micropreparative isolation of pharmacologically active isoflavones from Trifolium L. species, Talanta 79 (2009) 46-53.

[80] D.L. Yongqiang Wanga, Y. Gao, H. Ding, S. Liu, X. Han, J. Gui, Subcritical ethanol extraction of flavonoids from Moringa oleifera leaf and evaluation of antioxidant activity, Food Chem. 218 (2017) 152-158.

[81] J. Xi, L. Yan, Optimization of pressure-enhanced solid-liquid extraction of flavonoids from Flos sophorae and evaluation of their antioxidant activity, Separ. Purif. Technol. 175 (2017) 170-176. 
[82] J. Xi, S. Luo, Pressure-enhanced solid-liquid extraction of rutin from Chinese scholar-tree flower: kinetic modeling of influential factors, Separ. Purif. Technol. 156 (2015) 809-816.

[83] B.M. Jae-Hyun Kang, S. Kim, Optimization by response surface methodology of lutein recovery from paprika leaves using accelerated solvent extraction, Food Chem. 205 (2016) 140-145.

[84] S.L.L. Zhan-Yi Zhao, Q. Zhang, Ya-Fang Li, Lu-Lu Dong, Optimization of ultrasound extraction of Alisma orientalis polysaccharides by response surface methodology and their antioxidant activities, Carbohydr. Polym. 119 (2015) 101-109.

[85] L.Y. Xinran Li, F. Chen, S. Li, J. Jia, H. Gu, An efficient homogenate-microwave-assisted extraction of flavonols and anthocyanins from blackcurrant marc: optimization using combination of Plackett-Burman design and Box-Behnken design, Ind. Crop. Prod. 94 (2016) 834-847.

[86] G. Woodward, P. Kroon, A. Cassidy, C. Kay, Anthocyanin stability and recovery: implications for the analysis of clinical and experimental samples, J. Agric. Food Chem. 57 (2009) 5271-5278.

[87] P.-X.Y. Bo He, Ling-Li Zhang, Xue-Yang Yue, J. Liang, J. Jiang, Xue-Ling Gao, Optimization of Ultrasound-Assisted Extraction of phenolic compounds and anthocyanins from blueberry (Vaccinium ashei) wine pomace, Food Chem. 204 (2016) 70-76.

[88] Y. Sun, X. Liao, Z. Wang, X. Hu, F. Chen, Optimization of microwave-assisted extraction of anthocyanins in red raspberries and identification of anthocyanin of extracts using high-performance liquid chromatography - mass spectrometry, Eur. Food Res. Technol 225 (2007) 511-523.

[89] A.G.W. Brigita Lapornik, M. Prošek, Comparison of extracts prepared from plant by-products using different solvents and extraction time, J. Food Eng. 71 (2005) 214-222.

[90] T.L. Swer, K. Chauhan, P.K. Paul, C. Mukhim, Evaluation of enzyme treatment conditions on extraction of anthocyanins from Prunus nepalensis L, Int. J. Biol. Macromol. 92 (2016) 867-871.

[91] M.M.H.B.B. Li, B. Smith, Extraction of phenolics from citrus peels: II. Enzyme-assisted extraction method, Separ. Purif. Technol. 48 (2006) 189-196.

[92] G. Danisman, E. Arslan, A. Kirca Toklucu, Kinetic analysis of anthocyanin degradation and polymeric colour formation in grape juice during heating, Czech J. Food Sci. Food Chem. 33 (2015) 103-108.

[93] Anne-Katrine Landbo, A.S. Meyer, Enzyme-assisted extraction of antioxidative phenols from black currant juice press residues (Ribes nigrum), J. Agric. Food Chem. 49 (2001) 3169-3177.

[94] E. Barzana, D. Rubio, R.I. Santamaria, O. Garcia-Correa, F. Garcia, V.E. Ridaura Sanz, A. López-Munguía, Enzyme-Mediated solvent extraction of carotenoids from marigold flower (Tagetes erecta), J. Agric. Food Chem. 50 (2002) 4491-4496.

[95] N.S.-K. Michelle, M. Feuereisen, M.G. Barraza, B.F. Zimmermann, A Schieber, Pressurized liquid extraction of anthocyanins and biflavonoids from Schinus terebinthifolius Raddi: a multivariate optimization,, Food Chem. 214 (2017) 564-571.

[96] D. Peña-Sanhueza, C. Inostroza-Blancheteau, A. Ribera-Fonseca, M Reyes-Díaz, Anthocyanins in berries and their potential use in human health, In: Superfood and Functional Food-the Development of Superfoods and Their Roles as Medicine. InTech, 2017.

[97] D. Wianowska, M. Wisniewski, Simplified procedure of silymarin extraction from Silybum marianum L. Gaertner, J. Chromatogr. Sci. 53 (2015) 366-372.

[98] F.J.B. Elena Roselló-Soto, C.M. Galanakis, M. Brnčić, V. Orlien, F.J. Trujillo, R. Mawson, K. Knoerzer, B.K. Tiwari, Clean recovery of antioxidant compounds from plant foods, by-products and algae assisted by ultrasounds processing. Modeling approaches to optimize processing conditions, Trends Food Sci. Technol. 42 (2015) 134-149.

[99] C.H. Cyrielle Corbin, T. Fidel, E.A. Leclerc, E. Barakzoy, N. Sagot, A. Falguiéres, S. Renouard, Jean-Philippe Blondeau, C. Ferroud, J. Doussot, E. Lainé, Development and validation of an efficient ultrasound assisted extraction of phenolic compounds from flax (Linum usitatissimum L.) seeds, Ultrason. Sonochem. 26 (2015) 176-185

[100] G.F.B. Estrella Espada-Bellido, M. Ferreiro-González, C. Carrera, M. Palma, C.G. Barroso, Optimization of the ultrasound-assisted extraction of anthocyanins and total phenolic compounds in mulberry (Morus nigra) pulp, Food Chem. 219 (2017) 23-32.

[101] W. Duan, S. Jin, G. Zhao, P. Sun, Microwave-assisted extraction of anthocyanin from Chinese bayberry and its effects on anthocyanin stability, Food Sci. Technol. 35 (2015) 524-530.

[102] V. Varadharajan, S. Shanmugam, A. Ramaswamy, Model generation and process optimization of microwave assisted aqueous extraction of anthocyanin from grape juice waste, J. Food Process. Eng. 40 (2017) e12486.

[103] I.S.C. Vahid Farzaneh, Modelling of microwave assisted extraction (MAE) of anthocyanins (TMA), J. Appl. Res. Med. Aromat. Plants (2017) https://doi.org/ 10.1016/J.JARMAP.2017.02.005.

[104] T. Wu, X. Qi, Y. Liu, J. Guo, R. Zhu, W. Chen, X. Zheng, T. Yu, Dietary supplementation with purified mulberry (Morus australis Poir) anthocyanins sup- presses body weight gain in high-fat diet fed C57BL/6 mice, Food Chem. 141 (2013) 482-487.

[105] P.L. Zhan Cai, Z. Qu, Y. Lan, S. Zhao, X. Ma, Q. Wan, P. Jing, Conventional, ultrasound-assisted, and accelerated-solvent extractions of anthocyanins from purple sweet potatoes, Food Chem. 197 (2016) 266-272.

[106] E.F. Mária Then, K. Szentmihályi, Á. Sárközi, V. Illés, Effect of sample handling on alkaloid and mineral content of aqueous extracts of greater celandine (Chelidonium majus L.), J. Chromatogr. A 889 (2000) 69-74.

[107] I.J. Seabra, M.E.M. Braga, H.C. de Sousa, Statistical mixture design investigation of $\mathrm{CO}_{2}-$ Ethanol- $\mathrm{H}_{2} \mathrm{O}$ pressurized solvent extractions from tara seed coat, J. Supercrit. Fluids 64 (2012) 9-18.

[108] Y.H. Choi, Y.W. Chin, J. Kim, S.H. Jeon, K.P. Yoo, Strategies for supercritical fluid extraction of hyoscyamine and scopolamine salts using basified modifiers, J. Chromatogr. A 863 (1999) 47-55.

[109] J. Xiao, B. Tian, B. Xie, E. Yang, J. Shi, Z. Sun, Supercritical fluid extraction and identification of isoquinoline alkaloids from leaves of Nelumbo nucifera Gaertn, Eur. Food Res. Technol 231 (2010) 407-414.

[110] N.A. Gañán, A.M.A. Dias, F. Bombaldi, J.A. Zygadlo, E.A. Brignole, H.C. de Sousa, M.E.M. Braga, Alkaloids from Chelidonium majus L.: fractionated supercritical CO2 extraction with co-solvents, Separ. Purif. Technol. 165 (2016) 199-207.

[111] Á. Sárközi, G. Janicsák, L. Kursinszki, Á. Kéry, Alkaloid composition of Chelidonium majus L. Studied by different chromatographic techniques, Chromatographia 63 (2006) S81-S86.

[112] J. Suchomelová, H. Bochořáková, H. Paulová, P. Musil, E. Taborska, HPLC quantification of seven quaternary benzo[c]phenanthridine alkaloids in six species of the family Papaveraceae, J. Pharmaceut. Biomed. Anal. 44 (2007) 283-287.

[113] X. Ruan, W.X. Cui, L. Yang, Z.H. Li, B. Liu, Q. Wang, Extraction of total alkaloids, peimine and peiminine from the flower of Fritillaria thunbergii Miq using supercritical carbon dioxide, J. $\mathrm{CO}_{2}$ Util 18 (2017) 283-293.

[114] R. Krska, C. Crews, Significance, chemistry and determination of ergot alkaloids: a review, Food Addit. Contam. 25 (2008) 722-731.

[115] U. Lauber, R. Schnaufer, M. Gredziak, Y. Kiesswetter, Analysis of rye grains and rye meals for ergot alkaloids, Mycotoxin Res. 21 (2005) 258-262.

[116] P.M. Scott, G.A. Lawrence, Analysis of ergot alkaloids in flour, J. Agric. Food Chem. 28 (1980) 1258-1261.

[117] J.D. Di Mavungu, S.V. Malysheva, M. Sanders, D. Larionova, J. Robbens, P. Dubruel, C. Van Peteghem, S. De Saeger, Development and validation of a new LC-MS/MS method for the simultaneous determination of six major ergot alkaloids and their corresponding epimers. Application to some food and feed commodities, Food Chem. 135 (2012) 292-303.

[118] C. Mueller, H.S. Klaffke, W. Krauthause, R. Wittkowski, Determination of ergot alkaloids in rye and rye flour, Mycotoxin Res. 22 (2006) 197-200.

[119] C. Mueller, S. Kemmlein, H. Klaffke, W. Krauthause, A. Preiss-Weigert, R. Wittkowski, A basic tool for risk assessment: a new method for the analysis of ergot alkaloids in rye and selected rye products,, Mol. Nutr. Food Res. 53 (2009) 500-507.

[120] G.M. Ware, G. Price, L. Carter, R.R. Eitenmiller, Liquid chromatographic preparative method for isolating ergot alkaloids, using a particle-loaded membrane extracting disk, J. AOAC Int 83 (2000) 1395-1399.

[121] S.V. Malysheva, J.D. Di Mavungu, I.Y. Goryacheva, S. De Saeger, A systematic assessment of the variability of matrix effects in LC-MS/MS analysis of ergot alkaloids in cereals and evaluation of method robustness, Anal. Bioanal. Chem. 405 (2013) 5595-5604

[122] R. Mohamed, E. Gremaud, J. Richoz-Payot, J.-C. Tabet, P.A. Guy, Quantitative determination of five ergot alkaloids in rye flour by liquid chromatography-electrospray ionisation tandem mass spectrometry, J. Chromatogr. A 1114 (2006) 62-72.

[123] R. Koeppen, T. Rasenko, S. Merkel, B. Moench, M. Koch, Novel solid-phase extraction for epimer-specific quantitation of ergot alkaloids in rye flour and wheat germ oil, J. Agric. Food Chem. 61 (2013) 10699-10707.

[124] C. Oellig, T. Melde, Screening for total ergot alkaloids in rye flour by planar solid phase extraction-fluorescence detection and mass spectrometry, J. Chromatogr. A 1441 (2016) 126-133.

[125] C. Oellig, W. Schwack, Planar solid phase extraction-a new clean-up concept in multi-residue analysis of pesticides by liquid chromatography-mass spectrometry, J. Chromatogr. A 1218 (2011) 6540-6547.

[126] C. Oellig, W. Schwack, Planar solid phase extraction clean-up and microliter-flow injection analysis-time-of-flight mass spectrometry for multi-residue screening of pesticides in food, J. Chromatogr. A 1351 (2014) 1-11.

[127] N. Kondamudi, J.K. Smith, O.M. McDougal, Determination of glycoalkaloids in potatoes and potato products by microwave assisted extraction, Am. J. Potato Res. 94 (2017) 153-159.

[128] Y. Bai, C. Li, J. Zhao, P. Zheng, Y. Li, Y. Pan, Y. Wang, A high yield method of extracting alkaloid from Aconitum coreanum by pulsed electric field, Chromatographia 76 (2013) 635-642. 
[129] S.S. Hosseini, F. Khodaiyan, M.S. Yarmand, Optimization of microwave assisted extraction of pectin from sour orange peel and its physicochemical properties, Carbohydr. Polym. 140 (2016) 59-65.

[130] G.J. Swamy, K. Muthukumarappan, Optimization of continuous and intermittent microwave extraction of pectin from banana peels, Food Chem. 220 (2017) 108-114.

[131] Z. Cheng, H. Song, X. Cao, Q. Shen, D. Han, F. Zhong, H. Hu, Y. Yang, Simultaneous extraction and purification of polysaccharides from Gentiana scabra Bunge by microwave-assisted ethanol-salt aqueous two-phase system, Ind. Crop. Prod. 102 (2017) 75-87.

[132] M. Shoaib, A. Shehzad, M. Omar, A. Rakha, H. Raza, H.R. Sharif, A. Shakeel, A. Ansari, S. Niazi, Inulin: properties, health benefits and food applications, Carbohydr. Polym. 147 (2016) 444-454

[133] Z. Zhu, J. He, G. Liu, F.J. Barba, M. Koubaa, L. Ding, O. Bals, N. Grimi, E. Vorobiev, Recent insights for the green recovery of inulin from plant food materials using non-conventional extraction technologies: a review, Innovat. Food Sci. Emerg. Technol. 33 (2016) 1-9.

[134] Z. Zhu, O. Bals, N. Grimi, E. Vorobiev, Pilot scale inulin extraction from chicory roots assisted by pulsed electric fields, Int. J. Food Sci. Technol. 47 (2012) 1361-1368.

[135] Z. Zhu, O. Bals, N. Grimi, L. Ding, E. Vorobiev, Qualitative characteristics and dead-end ultrafiltration of chicory juice obtained from pulsed electric field treated chicories, Ind. Crop. Prod. 46 (2013) 8-14.

[136] Z. Zhu, O. Bals, N. Grimi, L. Ding, E. Vorobiev, Better damage of chicory tissue by combined electroporation and ohmic heating for solute extraction, Food Bioprod. Process. 94 (2015) 248-254.

[137] S. Wu, M. Lu, S. Wang, Amylase-assisted extraction and antioxidant activity of polysaccharides from Gracilaria lemaneiformis, 3 Biotech 7 (2017) 38.

[138] C.O. Perera, G.M. Yen, Functional properties of carotenoids in human health, Int. J. Food Prop. 10 (2007) 201-230.

[139] S. Roohinejad, I. Oey, D.W. Everett, B.E. Niven, Evaluating the effectiveness of $\beta$-carotene extraction from pulsed electric field-treated carrot pomace using oil-in-water microemulsion, Food Bioprocess Tech 7 (2014) 3336-3348.

[140] I.F. Strati, V. Oreopoulou, Recovery of carotenoids from tomato processing by-products-A review, Food Res. Int. 65 (2014) 311-321.

[141] P. Nath, C. Kaur, S.G. Rudra, E. Varghese, Enzyme-assisted extraction of carotenoid-rich extract from red capsicum (Capsicum annuum), Agric. Res. 5 (2016) 193-204.

[142] C.W. Lu, Y.G. Yin, Q.Y. Yu, Optimized extraction of ginsenosides from ginseng root (Panax ginseng CA meyer) by pulsed electric field combined with commercial enzyme, J. Food Process. Preserv. 41 (2017) e12766.

[143] S. Sasidharan, Y. Chen, D. Saravanan, K.M. Sundram, L.Y. Latha, Extraction, isolation and characterization of bioactive compounds from plants' extracts, Afr. J. Tradit., Complementary Altern. Med. 8 (2011) 1-10.

[144] C. Proestos, M. Komaitis, Application of microwave-assisted extraction to the fast extraction of plant phenolic compounds, LWT- Food Sci. Technol 41 (2008) 652-659.

[145] M.C. Bubalo, S. Vidović, I.R. Redovniković, S. Jokić, Green solvents for green technologies, J. Chem. Technol. Biotechnol. 90 (2015) 1631-1639.

[146] E.L. Smith, A.P. Abbott, K.S. Ryder, Deep eutectic solvents (DESs) and their applications, Chem. Rev. 114 (2014) 11060-11082.

[147] A.P. Abbott, D. Boothby, G. Capper, D.L. Davies, R.K. Rasheed, Deep eutectic solvents formed between choline chloride and carboxylic acids: versatile alternatives to ionic liquids, J. Am. Chem. Soc. 126 (2004) 9142-9147.

[148] T. Bosiljkov, F. Dujmić, M.C. Bubalo, J. Hribar, R. Vidrih, M. Brnčić, E. Zlatic, I.R. Redovniković, S. Jokić, Natural deep eutectic solvents and ultrasound-assisted extraction: Green approaches for extraction of wine lees anthocyanins, Food Bioprod. Process. 102 (2017) 195-203.

[149] E. Durand, J. Lecomte, P. Villeneuve, From green chemistry to nature: the versatile role of low transition temperature mixtures, Biochimie 120 (2016) 119-123.

[150] M. Jancheva, S. Grigorakis, S. Loupassaki, D.P. Makris, Optimized extraction of antioxidant polyphenols from Satureja thymbra using newly designed glycerol-based natural low-transition temperature mixtures (LTTMs), J. Appl. Res. Med. Aromat. Plants 6 (2017) 31-40.

[151] S. Gouin, Microencapsulation: industrial appraisal of existing technologies and trends, Trends Food Sci. Technol. 15 (2004) 330-347.

[152] V. Đorđević, B. Balanč, A. Belščak-Cvitanović, S. Lević, K. Trifković, A Kalušević, I. Kostić, D. Komes, B. Bugarski, V. Nedović, Trends in encapsulation technologies for delivery of food bioactive compounds, Food Eng.Rev. 7 (2015) 452-490

[153] A.C. Diamanti, P.E. Igoumenidis, I. Mourtzinos, K. Yannakopoulou, V.T. Karathanos, Green extraction of polyphenols from whole pomegranate fruit using cyclodextrins, Food Chem. 214 (2017) 61-66.

[154] A. Berna, A. Cháfer, J.B. Montón, S. Subirats, High-pressure solubility data of system ethanol (1)+ catechin (2)+ CO 2(3), J. Supercrit. Fluids 20 (2001) $157-162$.
[155] I.J. Seabra, M.E.M. Braga, M.T. Batista, H.C. de Sousa, Effect of solvent $\left(\mathrm{CO}_{2} /\right.$ ethanol/ $\left.\mathrm{H}_{2} \mathrm{O}\right)$ on the fractionated enhanced solvent extraction of anthocyanins from elderberry pomace, J. Supercrit. Fluids 54 (2010) 145-152.

[156] C.J. Chang, K.L. Chiu, Y.L. Chen, C.Y. Chang, Separation of catechins from green tea using carbon dioxide extraction, Food Chem. 68 (2000) 109-113.

[157] J.M. DeSimone, Practical approaches to green solvents, Science 297 (2002) 799-803.

[158] G.T. Wei, Z. Yang, C.J. Chen, Room temperature ionic liquid as a novel medium for liquid/liquid extraction of metal ions, Anal. Chim. Acta 488 (2003) $183-192$

[159] L. Ye, C. Yang, W. Li, J. Hao, M. Sun, J. Zhang, Z. Zhang, Evaluation of volatile compounds from Chinese dwarf cherry (Cerasus humilis (Bge.) Sok.) germplasms by headspace solid-phase microextraction and gas chromatography-mass spectrometry, Food Chem. 217 (2017) 389-397.

[160] L. Vidal, E. Psillakis, C.E. Domini, N. Grané, F. Marken, A. Canals, An ionic liquid as a solvent for headspace single drop microextraction of chlorobenzenes from water samples, Anal. Chim. Acta 584 (2007) 189-195.

[161] J.F. Liu, G.B. Jiang, Y.G. Chi, Y.Q. Cai, Q.X. Zhou, J.T. Hu, Use of ionic liquids for liquid-phase microextraction of polycyclic aromatic hydrocarbons, Anal. Chem. 75 (2003) 5870-5876.

[162] K. Shimojo, K. Nakashima, N. Kamiya, M. Goto, Crown ether-mediated extraction and functional conversion of cytochrome $\mathrm{c}$ in ionic liquids, Biomacromolecules 7 (2006) 2-5.

[163] S. Li, C. He, H. Liu, K. Li, F. Liu, Ionic liquid-based aqueous two-phase system, a sample pretreatment procedure prior to high-performance liquid chromatography of opium alkaloids, J. Chromatogr. B 826 (2005) 58-62.

[164] H. Passos, M.G. Freire, J.A. Coutinho, Ionic liquid solutions as extractive solvents for value-added compounds from biomass, Green Chem. 16 (2014) 4786-4815.

[165] D. Badica, Mass Transfer Intensification Techniques in Liquid Phase, Universitatea "Politehnica" Bucuresti.Bucuresti, 2001

[166] K. Vilkhu, R. Mawson, L. Simons, D. Bates, Applications and opportunities for ultrasound assisted extraction in the food industry-A review, Innovat. Food Sci. Emerg. Technol. 9 (2008) 161-169.

[167] P. García-Segovia, A. Andrés-Bello, J. Martínez-Monzó, Rehydration of air-dried Shiitake mushroom (Lentinus edodes) caps: comparison of conventional and vacuum water immersion processes, LWT-Food Sci. Technol 44 (2011) 480-488.

[168] Y. Tian, Y. Zhao, J. Huang, H. Zeng, B. Zheng, Effects of different drying methods on the product quality and volatile compounds of whole shiitake mushrooms, Food Chem. 197 (2016) 714-722.

[169] H.N.T. Pham, V. Nguyen, Q. Vuong, M.C. Bowyer, C.J. Scarlett, Bioactive compound yield and antioxidant capacity of Helicteres hirsuta Lour. stem as affected by various solvents and drying methods, J. Food Process. Preserv. 41 (2017) e12879.

[170] V.T. Nguyen, Q. Van Vuong, M.C. Bowyer, I.A. Van Altena, C.J. Scarlett, Effects of different drying methods on bioactive compound yield and antioxidant capacity of Phyllanthus amarus, Dry. Technol. 33 (2015) 1006-1017.

[171] R.R. Mphahlele, O.A. Fawole, N.P. Makunga, U.L. Opara, Effect of drying on the bioactive compounds, antioxidant, antibacterial and antityrosinase activities of pomegranate peel, BMC Complement. Altern. Med 16 (2016), 143-143.

[172] J.P. Bartley, A.L. Jacobs, Effects of drying on flavour compounds in Australian-grown ginger (Zingiber officinale), J. Sci. Food Agric. 80 (2000) 209-215.

[173] A.D.S. e Silva, L.M. Moreira, W.T. de Magalhães, W.L. Farias, M.V.P. Rocha, A.K.P. Bastos, Extraction of biomolecules from Spirulina platensis using non-conventional processes and harmless solvents, J. Environ. Chem. Eng 5 (2017) 2101-2106.

[174] J. Sun, X.E. Zhao, J. Dang, X. Sun, L. Zheng, J. You, X. Wang, Rapid and sensitive determination of phytosterols in functional foods and medicinal herbs by using UHPLC-MS/MS with microwave assisted derivatization combined with dual ultrasound assisted dispersive liquid-liquid microextraction, J Sep Sci. 40 (2017) 725-732

[175] M.M. Moreira, M.F. Barroso, A. Boeykens, H. Withouck, S. Morais, C Delerue-Matos, Valorization of apple tree wood residues by polyphenols extraction: comparison between conventional and microwave-assisted extraction, Ind. Crop. Prod. 104 (2017) 210-220.

[176] A.M. Galan, I. Calinescu, A. Trifan, C. Winkworth-Smith, M. Calvo-Carrascal, C. Dodds, E. Binner, New insights into the role of selective and volumetric heating during microwave extraction: investigation of the extraction of polyphenolic compounds from sea buckthorn leaves using microwave-assisted extraction and conventional solvent extraction, Chem. Eng. Process 116 (2017) 29-39.

[177] N. Jeyaratnam, A.H. Nour, R. Kanthasamy, A.H. Nour, A.R. Yuvaraj, J.O. Akindoyo, Essential oil from Cinnamomum cassia bark through hydrodistillation and advanced microwave assisted hydrodistillation, Ind. Crop. Prod. 92 (2016) 57-66. 
[178] H.S. Kusuma, M. Mahfud, Microwave-assisted hydrodistillation for extraction of essential oil from patchouli (Pogostemoncablin) leaves, Period. Polytech.Chem. Eng 61 (2017) 82.

[179] J. Dai, V. Orsat, G.V. Raghavan, V. Yaylayan, Investigation of various factors for the extraction of peppermint (Mentha piperita L.) leaves, J. Food Eng. 96 (2010) 540-543.

[180] M.A. Bezerra, R.E. Santelli, E.P. Oliveira, L.S. Villar, L.A. Escaleira, Response surface methodology (RSM) as a tool for optimization in analytical chemistry, Talanta 76 (2008) 965-977.

181] A. Altemimi, D.A. Lightfoot, M. Kinsel, D.G. Watson, Employing response surface methodology for the optimization of ultrasound assisted extraction of lutein and $\beta$-carotene from spinach, Molecules 20 (2015) 6611-6625.

[182] M. Biesaga, Influence of extraction methods on stability of flavonoids, J. Chromatogr. A 1218 (2011) 2505-2512.

[183] F. Chemat, G.A.A. Cravotto, Microwave-assisted Extraction for Bioactive Compounds, ED. 1, Springer US, 2013.

[184] X. Xiao, W. Song, J. Wang, G. Li, Microwave-assisted extraction performed in low temperature and in vacuo for the extraction of labile compounds in food samples, Anal. Chim. Acta 712 (2012) 85-93.

[185] F.J. Barba, O. Parniakov, S.A. Pereira, A. Wiktor, N. Grimi, N. Boussetta, J.A. Saraiva, J. Raso, O. Martin-Belloso, D. Witrowa-Rajchert, N. Lebovka, Current applications and new opportunities for the use of pulsed electric fields in food science and industry, Food Res. Int. 77 (2015) 773-798.

[186] S. Zhao, O.D. Baik, Y.J. Choi, S.M. Kim, Pretreatments for the efficient extraction of bioactive compounds from plant-based biomaterials, Crit. Rev. Food Sci. Nutr. 54 (2014) 1283-1297.

[187] J. Dai, R.J. Mumper, Plant phenolics: extraction, analysis and their antioxidant and anticancer properties, Molecules 15 (2010) 7313-7352.

[188] J. Shi, H. Nawaz, J. Pohorly, G. Mittal, Y. Kakuda, Y. Jiang, Extraction of polyphenolics from plant material for functional foods-Engineering and technology, Food Rev. Int. 21 (2005) 139-166.

[189] N. Rombaut, A.S. Tixier, A. Bily, F.Chemat, Green extraction processes of natural products as tools for biorefinery, Biofuels, Bioprod. Biorefin 8 (2014) 530-544.

[190] M. Dhibi, M. Issaoui, F. Brahmi, B. Mechri, A. Mnari, I. Cheraif, F. Skhiri, N Gazzah, M. Hammami, Nutritional quality of fresh and heated Aleppo pine(Pinus halepensis Mill.) seed oil: trans-fatty acid isomers profiles and antioxidant properties, J. Food Sci. Technol. 51 (2014) 1442-1452.

[191] M. Li, Y. Wang, X. Zhou, J. Liu, Y. Chang, D. Yu, Study on cold-pressed of Korean pine seed oil, Food Ind 21 (2000) 79-81.

[192] C.M. Cater, K.C. Rhee, R.D. Hagenmaier, K.F. Mattil, Aqueous extraction - an alternative oilseed milling process, J. Am. Oil Chem. Soc. 51 (1974) 137-141.

[193] H.N. Johansen, V. Glits , K.E. Bach Knudsen, Influence of extraction solvent and temperature on the quantitative determination of oligosaccharides from plant materials by high-performance liquid chromatography, J. Agric. Food Chem. 44 (1996) 1470-1474.

[194] J. Li, Y. Zu, M. Luo, C. Gu, C. Zhao, T. Efferth, Y. Fu, Aqueous enzymatic process assisted by microwave extraction of oil from yellow horn (Xanthoceras sorbifolia Bunge.) seed kernels and its quality evaluation, Food Chem. 138 (2013) 2152-2158

[195] L.C. Dickey, D.B. Johnston, M.J. Kurantz, A. McAloon, R.A. Moreau, Modification of aqueous enzymatic oil extraction to increase the yield of corn oil from dry fractionated corn germ, Ind. Crop. Prod. 34 (2011) 845-850.

[196] S. Shah, A. Sharma, M.N. Gupta, Extraction of oil from Jatropha curcasL. seed kernels by combination of ultrasonication and aqueous enzymatic oil extraction, Bioresour. Technol. 96 (2005) 121-123.

[197] A. Pare, A. Nema, V.K. Singh, B.L. Mandhyan, Combined effect of ohmic heating and enzyme assisted aqueous extraction process on soy oil recovery, J. Food Sci. Technol. 51 (2014) 1606-1611.

[198] Y.C. Zhang, C.M. Liu, Y.J. Qi, S.N. Li, Y. Pan, Y.C. Li, Circulating ultrasound-assisted extraction counter current chromatography, and liquid chromatography for the simultaneous extraction, isolation, and analysis of the constituents of Uncaria tomentosa, J. Chromatogr. A 1388 (2015a) 36-42.

[199] Y.C. Zhang, C.M. Liu, J. Li, Y.J. Qi, Y.C. Li, S.N. Li, Development of ultrasound-assisted dynamic extraction and its combination with CCC and CPC for simultaneous extraction and isolation of phytochemicals, Ultrason. Sonochem. $26(2015 b) 111-118$

[200] F. Chen, Q. Zhang, H. Gu, L. Yang, An approach for extraction of kernel oil from Pinus pumila using homogenate-circulating ultrasound in combination with an aqueous enzymatic process and evaluation of its antioxidant activity, J. Chromatogr. A 1471 (2016) 68-79.

[201] S. Latif, F. Anwar, Aqueous enzymatic sesame oil and protein extraction, Food Chem. 125 (2011) 679-684.

[202] F. Amarni, H. Kadi, Kinetics study of microwave-assisted solvent extraction of oil from olive cake using hexane: comparison with the conventional extraction, Innovat. Food Sci. Emerg. Technol. 11 (2010) 322-327.

[203] S. Azadmard-Damirchi, F. Habibi-Nodeh, J. Hesari, M. Nemati, B.F. Achachlouei, Effect of pretreatment with microwaves on oxidative stability and nutraceuticals content of oil from rapeseed, Food Chem. $121(2010)$ $1211-1215$

[204] M.L. Clodoveo, R.H. Hbaieb, Beyond the traditional virgin olive oil extraction systems: searching innovative and sustainable plant engineering solutions, Food Res. Int. 54 (2011) 1926-1933.

[205] M. Taghvaei, S.M. Jafari, E. Assadpoor, S. Nowrouzieh, O. Alishah, Optimization of microwave-assisted extraction of cottonseed oil and evaluation of its oxidative stability and physicochemical properties, Food Chem. 160 (2014) 90-97.

[206] A. Tamborrino, R. Romaniello, R. Zagaria, A. Leone, Microwave-assisted treatment for continuous olive paste conditioning: impact on olive oil qualityand yield, Biosyst. Eng. 127 (2014) 92-102.

[207] A. Tsukui, H.S. Júnior, S.S. Oigman, R.O.M.A. De Souza, H.R. Bizzo, C.M. Rezende, Microwave-assisted extraction of green coffee oil and quantification of diterpenes by HPLC, Food Chem. 164 (2014) 266-271

[208] F. Chemat, M. Vian, F. Visioni, Microwave hydrodiffusion for isolation of natural products, European Patent EP.1 (2008) 749

[209] B.N. Lee, Microwave apparatus and method of extracting essential oils, essence, and pigments with gas flow.U.S. Patent 8,282,789. (2012)

[210] D.K. Yanı, Alternative to traditional olive pomace oil extraction systems: microwave-assisted solvent extraction of oil from wet olive pomace, LWT - Food Sci. Technol 77 (2017) 45-51.

[211] E. Uquiche, M. Jeréz, J. Ortíz, Effect of pretreatment with microwaves on mechanical extraction yield and quality of vegetable oil from Chilean hazelnuts (Gevuina avellana Mol), Innovat. Food Sci. Emerg. Technol. 9 (2008) 495-500.

[212] M. Yang, F. Huang, C. Liu, C. Zheng, Q. Zhou, H. Wang, Influence of microwave treatment of rapeseed on minor components content and oxidative stability of oil, Food Bioprocess Tech 6 (2013) 3206-3216.

[213] G. Ren, W. Zhang, S. Sun, X. Duan, Z. Zhang, Enhanced extraction of oil from flaxseed (Linum usitatissimum L.) using microwave pre-treatment, J. Oleo Sci. 64 (2015) 1043-1047.

[214] M. Rahimi-Nasrabadi, M.B. Gholivand, A. Vatanara, S. Pourmohamadian, A.R. Najafabadi, H. Batooli, Comparison of essential oil composition of Eucalyptus oleosa obtained by supercritical carbon dioxide and hydrodistillation, J. Herbs, Spices, Med. Plants 18 (2012) 318-330.

[215] M. Hassas-Roudsari, P.R. Chang, R.B. Pegg, R.T. Tyler, Antioxidant capacity of bioactives extracted from canola meal by subcritical water, ethanolic and hot water extraction, Food Chem. 114 (2009) 717-726.

[216] M.H. Eikani, F. Golmohammad, M. Mirza, S. Rowshanzamir, Extraction of volatile oil from cumin (Cuminum cyminum L.) with superheated water, J. Food Process. Eng. 30 (2007) 255-266.

[217] M.Z. Ozel, H. Kaymaz, Superheated water extraction, steam distillation and Soxhlet extraction of essential oils of Origanum onites, Anal. Bioanal. Chem. 379 (2004) 1127-1133.

[218] M.Z. Özel, F. Göğüş, J.F. Hamilton, A.C. Lewis, Analysis of volatile components from Ziziphora taurica subsp. tauricaby steam distillation, superheated-water extraction, and direct thermal desorption with $\mathrm{GC} \times \mathrm{GC}-\mathrm{TOFMS}$, Anal. Bioanal. Chem. 382 (2005) 115-119.

[219] H. Teng, Y.H. Choi, Optimization of ultrasonic-assisted extraction of bioactive alkaloid compounds from rhizoma coptidis (Coptis chinensisFranch.) using response surface methodology, Food Chem. 142 (2014) 299-305.

[220] J.H. Kwon, J.M. Bélanger, J.R. Paré, Optimization of microwave-assisted extraction (MAP) for ginseng components by response surface methodology, J. Agric. Food Chem. 51 (2003) 1807-1810.

[221] M. Zhong, K.L. Huang, J.G. Zeng, S. Li, J.M. She, G. Li, L. Zhang, Optimization of microwave-assisted extraction of protopine and allocryptopine from stems of Macleaya cordata (Willd) R. Br. using response surface methodology, J. Sep. Sci. 33 (2010) 2160-2167.

[222] X. Wang, Q. Wu, Y. Wu, G. Chen, W. Yue, Q. Liang, Response surface optimized Ultrasonic-Assisted extraction of flavonoids from Sparganii Rhizom and evaluation of their in vitro antioxidant activities, Molecules 17 (2012) 6769-6783.

[223] D.T. Xie, Y.Q. Wang, Y. Kang, Q.F. Hu, N.Y. Su, J. M. Huang, C.T. Che, J.X. Guo, Microwave-assisted extraction of bioactive alkaloids from Stephania sinica, J. Sep. Purification Technol. 130 173-181.

[224] Y.V. Chavan, R.S. Singhal, Separation of polyphenols and arecoline from areca nut (Areca catechu L.) by solvent extraction, its antioxidant activity, and identification of polyphenols, J. Sci. Food Agric. 93 (2013) 2580-2589.

[225] L. Yang, Z. Zhong-hua, Optimize the process of ionic liquid-based ultrasonic-assisted extraction of aesculin and aesculetin from Cortex fraxini by response surface methodology, Chem. Eng. J. 175 (2011) 539-547.

[226] L.C. Zhao, J. Liang, W. Li, K.M. Cheng, X. Xia, X. Deng, G.L. Yang, The use of response surface methodology to optimize the ultrasound-assisted extraction of five anthraquinones from Rheum palmatum L, Molecules 16 (2011) 5928-5937.

[227] I.S. Sanal, E.U. Bayraktar, U. Mehmetoglu, A. Calimli, Determination of optimum conditions for SC-(CO2 + ethanol) extraction of betacarotene from apri- 
cot pomace using response surface methodology, J. Supercrit. Fluids 34 (2005) 331-338.

[228] T. Hu, Y.Y. Guo, Q.F. Zhou, X.K. Zhong, L. Zhu, J.H. Piao, J. Chen, J.G. Jiang, Optimization of ultrasonic-assisted extraction of total saponins from Eclipta prostrasta L. using response surface methodology, J. Food Sci. 77 (2012) C975-C982.

[229] J.P. Fan, J. Cao, X.H. Zhang, J.Z. Huang, T. Kong, S. Tong, Z.Y. Tian, Y.L. Xie, R. Xu, J.H. Zhu, Optimization of ionic liquid based ultrasonic assisted extraction of puerarin from Radix Puerariae Lobatae by response surface methodology, Food Chem. 135 (2012) 2299-2306.

[230] T. Belwal, L. Giri, I.D. Bhatt, R.S. Rawal, V. Pande, An improved method for extraction of nutraceutically important polyphenolics from Berberis jaeschkeana CK Schneid fruits, Food Chem. 230 (2017) 657-666.

[231] T. Belwal, I.D. Bhatt, R.S. Rawal, V. Pande, Microwave-assisted extraction (MAE) conditions using polynomial design for improving antioxidant phytochemicals in Berberis asiaticaRoxb. ex DC. leaves, Ind. Crop. Prod. 95 (2017) 393-403.

[232] H. Wang, Y. Liu, S. Wei, Z. Yan, Application of response surface methodology to optimise supercritical carbon dioxide extraction of essential oil from Cyperus rotundus Linn, Food Chem. 132 (2012) 582-587.

[233] B. Liu, F. Guo, Y. Chang, H. Jiang, Q. Wang, Optimization of extraction of evodiamine and rutaecarpine from fruit of Evodia rutaecarpa using modified supercritical $\mathrm{CO}_{2}$, J. Chromatogr. A 1217 (2010) 7833-7839.

[234] H. Wijngaard, N. Brunton, The optimization of extraction of antioxidants from apple pomace by pressurized liquids,, J. Agric. Food Chem. 57 (2009) 10625-10631.

[235] M.B. Hossain, A. Rawson, I. Aguiló-Aguayo, N.P. Brunton, D.K. Rai, Recovery of steroidal alkaloids from potato peels using pressurized liquid extraction, Molecules 20 (2015) 8560-8573.

[236] X. Yin, Q. You, Z. Jiang, Optimization of enzyme assisted extraction of polysaccharides from Tricholoma matsutake by response surface methodology, Carbohydr. Polym. 86 (2011) 1358-1364.

[237] W. Zhao, Z. Yu, J. Liu, Y. Yu, Y. Yin, S. Lin, F. Chen, Optimized extraction of polysaccharides from corn silk by pulsed electric field and response surface quadratic design, J. Sci. Food Agric. 91 (2011) 2201-2209.
[238] E. Puertolas, O. Cregenzán, E. Luengo, I. Álvarez, J. Raso, Pulsed-electric-field-assisted extraction of anthocyanins from purple-fleshed potato, Food Chem. 136 (2013) 1330-1336.

[239] X. Xu, G. Yanxiang, L. Guangmin, W. Qi, Z. Jian, Optimization of supercritical carbon dioxide extraction of sea buckthorn (Hippophaë thamnoides L.) oil using response surface methodology, LWT - Food Sci. Technol 41 (2008) $1223-1231$

[240] L. Ji, Z. Yuan-Gang, F. Yu-Jie, Y. Yu-Chun, L. Shuang-Ming, L. Zheng-Nan, W. Michael, Optimization of microwave-assisted extraction of triterpene saponins from defatted residue of yellow horn (Xanthoceras sorbifolia Bunge.) kernel and evaluation of its antioxidant activity, Innov. Food Sci. Emerg. Tech 11 (2010) 637-643.

[241] S. Đurđevića, S. Milovanović, K. Šavikin, M. Ristić, N. Menković, D. Pljevljakušić, S. Petrović, A. Bogdanović, Improvement of supercritical CO2 and n-hexane extraction of wild growing pomegranate seed oil by microwave pretreatment, Ind. Crop. Prod. 104 (2017) 21-27.

[242] H. Ullaha, C. Devi, W. Maizatul, S. Shaharun, Comparative assessment of various extraction approaches for the isolation of essential oil from Polygonum minus using ionic liquids, J. King Saud Univ. Sci. (2017) https://doi.org/10.1016/ j.jksus.2017.05.014.

[243] E.O. Ajayi, A.P. Sadimenko, A.J. Afolayan, GC-MS evaluation of Cymbopogon citratus (DC) Stapf oil obtained using modified hydrodistillation and microwave extraction methods, Food Chem. 209 (2016) 262-266.

[244] A. Bampouli, K. Konstantina, P. Georgios, L. Vasiliki, K. Magdalini, G.M. Kostis, Comparison of different extraction methods of Pistacia lentiscus var. chia leaves: yield, antioxidant activity and essential oil chemical composition, J. Appl. Res. Med. Aromat. Plants 1 (2014) 81-91.

[245] G. Nonviho, P. Cédric, M. Lionel, K.C.S. Dominique, B. Nicolas, Lophira lanceolata seed oil extraction method (ancestral or modern) modifies the properties of the oil, Ind. Crop. Prod. 67 (2015) 49-54.

[246] S. Chanioti, C. Tzai, Optimization of ultrasound-assisted extraction of oil from olive pomace using response surface technology: oil recovery, unsaponifiable matter, total phenol content and antioxidant activity, LWT - Food Sci. Technol 79 (2017) 178-189. 